\title{
ESTUDO COMPARATIVO ENTRE PROPRIEDADES TECNOLÓGICAS DE ROCHAS AGLOMERADAS E ROCHAS NATURAIS
}

\author{
COMPARATIVE STUDY BETWEEN TECHNOLOGICAL PROPERTIES OF AGGLOMERATED \\ AND NATURAL STONES
}

\author{
Abiliane de Andrade PAZETO' ${ }^{1}$, Tânia Cleiciane Barbosa SOUZA², \\ Bruna Xavier FAITANIN ${ }^{1}$ \\ ${ }^{1}$ Centro de Tecnologia Mineral, CETEM, Rodovia Cachoeiro Alegre, Km 05, Bloco 10, Fazenda Morro Grande. Cachoeiro de \\ Itapemirim-ES. E-mails: apazeto@gmail.com; brunna_faitanin@hotmail.com \\ ${ }^{2}$ Programa de Pós-graduação em Tecnologias de Produção de Rochas Ornamentais, Instituto Federal do Espírito Santo/IFES - \\ Campus Cachoeiro de Itapemirim. Rodovia ES-482 (Cachoeiro-Alegre), Fazenda Morro Grande - Cachoeiro de Itapemirim, ES. \\ E-mail: escreviparatania@gmail.com
}

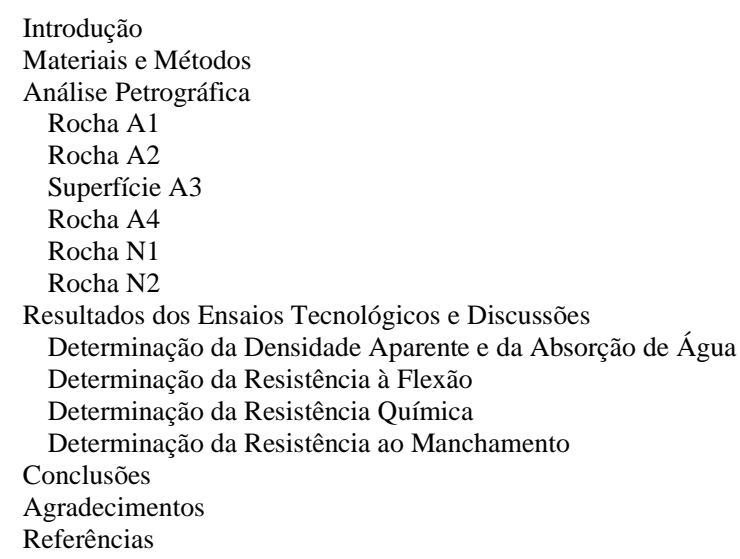

RESUMO - O Brasil é $5^{\circ}$ maior produtor de rochas ornamentais do mundo. No entanto, nos últimos anos têm crescido no país a importação e produção de rochas aglomeradas, que já se tornaram a maior concorrente das rochas naturais no acabamento de obras civis. Apesar desse crescente consumo, não há na maioria das vezes adequado conhecimento das propriedades tecnológicas desse material artificial por parte dos especificadores e consumidores, tornando sua aplicação empírica e podendo ocasionar degradações diversas em função do uso. Por outro lado, existe no meio comercial o sentimento de que os aglomerados possuem durabilidade superior às rochas naturais, sem haver, no entanto, embasamento científico. O objetivo deste trabalho foi determinar e comparar as propriedades petrográficas e o comportamento tecnológico de quatro rochas aglomeradas e duas rochas naturais com distintos aspectos mineralógicos e texturais visando, com isso, o estabelecimento de parâmetros capazes de explicar e/ou prever o desempenho físico-mecânico e químico dessas rochas quando em uso. Os resultados tecnológicos revelam que tanto as rochas aglomeradas quanto as naturais apresentaram desempenho satisfatório, qualificando-os para uso ornamental e revestimento. No entanto, para os índices físicos, um dos quartzitos apresentou desempenho superior ao de um dos materiais artificiais.

Palavras-chave: Caracterização tecnológica. Petrografia. Rochas aglomeradas. Rochas naturais.

ABSTRACT - Brazil is the fifth largest producer of ornamental stones in the world. However, in recent years the import and production of agglomerated stones has grown in the country, and such material has already become the biggest competitor of natural stones in civil construction. Despite this growing consumption, most of the time the specifiers and final consumer do not have proper knowledge about the technological properties of this artificial material, turning its application empirical and may cause degradations depending on the use. On the other hand, there is a feeling in the market that agglomerated have superior durability to natural stones, without any scientific basis. The objective of this work was to determine and compare the petrographic properties and the technological behavior of four agglomerated and two natural stones with different mineralogical and textural aspects, aiming the establishment of parameters capable of explaining and/or predicting the physical-mechanical and chemical performance of these materials when in use. The technological results reveal that both the agglomerated and the natural stones presented satisfactory performance, qualifying them for ornamental and covering purposes. However, for the physical indices, one of the quartzites performed better than one of the artificial materials.

Keywords: Technological characterization. Petrography. Agglomerated stones. Natural stones.

\section{INTRODUÇÃO}

O Brasil é o $5^{\circ}$ maior produtor de rochas naturais do globo, tendo produzido em 2018 mais de 9 milhões de toneladas de rochas distribuídas em 1.400 tipos comerciais (Chiodi Filho, 2019).
O principal emprego dessas rochas dá-se como material de construção, principalmente no revestimento de pisos e fachadas.

Não obstante a ampla diversidade geológica 
do país, com o avanço da tecnologia novos materiais surgiram como alternativa frente as rochas naturais e aos produtos cerâmicos.

Dentro desse contexto, as rochas aglomeradas, conhecidas no meio comercial como "superfícies de quartzo" têm se tornado a principal concorrente da rocha natural para o acabamento de obras civis.

Como reflexo da grande aceitação comercial e do aumento na demanda, em 2018 as importações brasileiras de aglomerados somaram US\$ 44,5 milhões e 64 mil toneladas, ultrapassando as importações de rochas naturais (Chiodi Filho, 2019).

Além disso, o Brasil já possui três fábricas nacionais de rochas aglomeradas e o país passou a exportar o produto.

De acordo com a norma EN 14618 (Associación Espanõla de Normalización y Certificación, 2011), define-se como rocha aglomerada o produto manufaturado em processo industrial a partir de uma mistura de agregados, aditivos e aglutinantes.

No geral esses agregados são quartzo, pó de granito ou de mármore em uma ampla faixa granulométrica. Podem ainda ser adicionados vidros coloridos ou espelhos para efeito decorativo.

Os aditivos são pigmentos para dar cor e outros compostos que conferem propriedades específicas, tais como bactericidas, enquanto que os aglutinantes são resinas termorrígidas do tipo epóxi ou poliéster, podendo ainda ser cimento hidráulico ou uma mistura deste com resina.

$O$ processo de fabricação das rochas aglomeradas dá-se em plantas industriais, onde é aplicado o método de vibro-compressão à vácuo (Lee et al., 2008). A primeira etapa consiste na dosagem e homogeneização das matériasprimas.

A mistura resultante é então distribuída em moldes no formato da chapa final, sendo em seguida submetida aos processos de vibração, compressão e vácuo simultaneamente. Por fim o molde é levado à estufa para curar por cerca de uma hora a $90^{\circ} \mathrm{C}$.

Depois de curadas as chapas são calibradas, polidas e armazenadas. As principais aplicações das rochas aglomeradas se dão em pias, bancadas e revestimento de áreas úmidas.

No mercado de rochas naturais, atualmente, apenas os materiais denominados "exóticos" possuem demanda similar a das rochas aglomeradas. Tal classificação comercial engloba rochas de cores e texturas incomuns que lhes confere alto valor agregado, sendo os quartizitos o principal representante desse grupo.

De acordo com Chiodi Filho (2019), em 2018 os quartizitos foram o mais importante produto de exportação de rochas, com um faturamento de US\$ 124 milhões e preço médio de US\$ 2.100/t.

As rochas têm características tecnológicas que refletem suas qualidades intrínsecas e constituem os parâmetros que guiam a seleção para quaisquer usos (Frascá et al., 2019). Como material de construção, torna-se fundamental determinar tais propriedades físico-mecânicas e químicas por meio de ensaios de caracterização tecnológica a fim de certificar se as mesmas atendem ao desempenho necessário em serviço e evitar patologias advindas da aplicação inadequada.

Por se tratar de produto relativamente novo no mercado, os estudos de caracterização tecnológica de rochas aglomeradas são escassos, prejudicando os especificadores quanto à correta aplicação desse produto em edificações, e os consumidores quanto aos parâmetros para definir sua escolha.

Ao mesmo tempo, apesar da caracterização das rochas naturais já ser prática extensiva em instituições de pesquisa e ensino (Yilmaz et al., 2010; Pazeto \& Artur, 2015; Bolonini \& Godoy, 2017), ainda existe uma grande lacuna quanto à interpretação desses resultados por parte de arquitetos e outros especificadores, fazendo com que esses tenham receio de aplicar as rochas naturais.

O cenário exposto evidencia a necessidade de continuar-se com estudos de caracterização tecnológica mais aprofundados, não só visando o melhor conhecimento das propriedades tecnológicas, mas principalmente para se obter parâmetros de comparação entre os materiais aglomerados e as rochas naturais que fomentem a competitividade do produto nacional no país e no exterior.

O objetivo deste trabalho foi determinar e comparar as propriedades petrográficas e tecnológicas de seis rochas, quatro aglomeradas e duas naturais, com distintos aspectos mineralógicos e texturais visando o estabelecimento de parâmetros capazes de explicar e/ou prever o desempenho físicomecânico e químico dessas rochas quando em uso. 


\section{MATERIAIS E MÉTODOS}

Para a realização deste estudo comparativo foram selecionados quatro materiais artificiais (três rochas aglomeradas e uma superfície sinterizada) de grande aceitação no mercado e duas rochas naturais da classe "exóticos”, cuja denominação ao longo do trabalho seguirá conforme a tabela 1.

Tabela 1 - Materiais artificiais e rochas naturais selecionadas para estudo.

\begin{tabular}{c|c}
\hline Nomenclatura & Tipo \\
\hline A1, A2 e A4 & Rocha aglomerada \\
\hline A3 & Superfície sinterizada \\
\hline N1 e N2 & Rocha natural \\
\hline
\end{tabular}

Os materiais denominados A1, A2 e A4 correspondem a rochas aglomeradas do tipo superfície de quartzo, provenientes de fornecedores distintos, mas fabricadas pelo mesmo método de vibro-compressão à vácuo (Lee et al., 2008). A composição se dá basicamente por agregados de quartzo, resina poliéster como aglutinante e pigmentos.

O material A3 corresponde a uma classe diferente de revestimento, denominado superfície ultracompacta sinterizada. No método de fabricação desse produto não é empregado nenhum tipo de aglutinante, apenas agregados minerais que são compactados e sinterizados a temperaturas de até $1300^{\circ} \mathrm{C}$, segundo informações do fabricante.

As rochas naturais N1 e N2 classificam-se petrograficamente como quartzitos. O tipo N1 é extraído no munícipio de Taiobeiras - MG e pertence à sequência metassedimentar da Formação Salinas (Santos, 2007). Por sua vez, o tipo N2 está associado à sequência de ortoquartzitos da Formação Rio do Ouro, Grupo Jacobina (Sampaio et al., 2001), sendo explorado no município de Pindobaçu - BA.

A análise petrográfica das rochas naturais foi realizada com auxílio de microscópio de luz transmitida Zeiss, modelo AXIOSKOP 40 AP, seguindo as instruções contidas na NBR 15844-1 (ABNT, 2015). Foram consideradas a composição modal, granulação média, microfissuras, grau de alteração mineral e contagem e determinação dos tipos de contato da trama mineral. Sempre que possível, os mesmos parâmetros foram analisados para as rochas aglomeradas, com exceção da superfície sinterizada A3. Como em lâmina petrográfica não foi possível identificar os componentes minerais, para esse material em específico efetuou-se apenas a fotomicrografia. A caracterização mineralógica foi então realizada por meio de difração de raios $\mathrm{X}$ (DRX) pelo método do pó em um difratômetro Bruker-D4 Endeavor, nas seguintes condições de operação: radiação Co $\mathrm{K} \alpha$ (35 kV/40 mA), velocidade do goniômetro de 0,02 - $2 \theta$ por passo e coletados de 5 a $80^{\circ} 2 \theta$. A composição química foi determinada em um espectrômetro de fluorescência de raios $\mathrm{X}$ Panalytical, modelo AxiosMax.

Após a análise petrográfica, as seis rochas foram submetidas a ensaios de caracterização tecnológica. Visto que a Associação Brasileira de Normas Técnicas - ABNT não possui metodologias de ensaios específicas para rochas aglomeradas, utilizou-se o pacote de normas europeu EN 14617. Para fins de comparação dos resultados, a caracterização dos quartzitos também foi efetuada seguindo as normas europeias. Os ensaios compreenderam a determinação da densidade aparente e da absorção d'água (AENOR, 2013), resistência à flexão pelo método de carga concentrada (AENOR, 2008), resistência química (AENOR, 2012a) e resistência ao manchamento (AENOR, 2012b). Os reagentes e substâncias do cotidiano utilizados nos ensaios químicos estão descritos na tabela 2.

Para o ensaio de resistência química, os possíveis danos causados à superfície dos materiais pelos reagentes foram mensurados em termos de variação de brilho, conforme recomendado em norma.

O ensaio de resistência ao manchamento requer somente uma avaliação visual, que é subjetiva. Assim, para tornar a variação de de cor e brilho mensurável e imparcial utilizou-se um espectrofotômetro portátil marca BYK-Gardner, modelo Spectro-guide, que determina a cor com base em coordenadas do sistema colorimétrico CIE 1931 no espaço cromático uniforme CIELAB (1976) (Tabela 1).

\section{Assim:}

a* e b* - representam as variações que envolvem o tom e o croma e que podem ser consideradas como sendo de cor, sendo que o eixo $a^{*}$ situa-se entre -50 (verde) e +50 (vermelho) e o $\mathrm{b}^{*}$ entre -50 (azul) e +50 (amarelo);

L* $^{*}$ indica a localização da cor no eixo claroescuro (preto para $L^{*}=0$ e branco para $L^{*}=100$ ). 
A variação total de cor $\Delta \mathrm{E}$ é calculada pela expressão:

$$
\Delta E=\sqrt{(\Delta a)^{2}+(\Delta b)^{2}+(\Delta L)^{2}}
$$

Onde:

$\Delta a=a_{\text {final }}-a_{\text {inicial }}, \Delta b=b_{\text {final }}-b_{\text {inicial }}$ e $\Delta L=L_{\text {final }}-L_{\text {inicial }}$
Os ensaios tecnológicos foram realizados no Laboratório de Caracterização Tecnológica de Rochas Ornamentais - LABRO do Centro de Tecnologia Mineral - CETEM/NRES e no laboratório homônimo do Instituto Federal do Espírito Santo, campus Cachoeiro de Itapemirim.

Tabela 2 - Reagentes e condições para os ensaios de resistência química e ao manchamento.

\begin{tabular}{|c|c|c|c|}
\hline & Reagentes & Condições & Tempo de ação \\
\hline \multirow{2}{*}{$\begin{array}{l}\text { Resistência química } \\
\text { EN 14617-10 }\end{array}$} & Ácido clorídrico (HCl) & $50 \%$ V/V, preparado à partir de solução 1N & $8 \mathrm{~h}$ \\
\hline & $\begin{array}{l}\text { Hidróxido de sódio } \\
(\mathrm{NaOH})\end{array}$ & $50 \%$ V/V, preparado à partir de solução $1 \mathrm{~N}$ & $8 \mathrm{~h}$ \\
\hline \multirow{5}{*}{$\begin{array}{c}\text { Resistência ao } \\
\text { manchamento } \\
\text { EN 14617-10 } \\
\text { Anexo A }\end{array}$} & Azeite & Acidez $\leq 0,50$ & $24 \mathrm{~h}$ \\
\hline & Café solúvel extra forte & Uma colher de chá de café + 200 ml de água & $24 \mathrm{~h}$ \\
\hline & Desinfetante & $\begin{array}{l}\text { Ingrediente ativo: 0,65\% de cloreto de } \\
\text { didecil dimetil amônio/cloreto de alquil } \\
\text { dimetil benzil amônio. }\end{array}$ & $24 \mathrm{~h}$ \\
\hline & Molho de tomate & - & $24 \mathrm{~h}$ \\
\hline & Suco de uva integral & - & $24 \mathrm{~h}$ \\
\hline
\end{tabular}

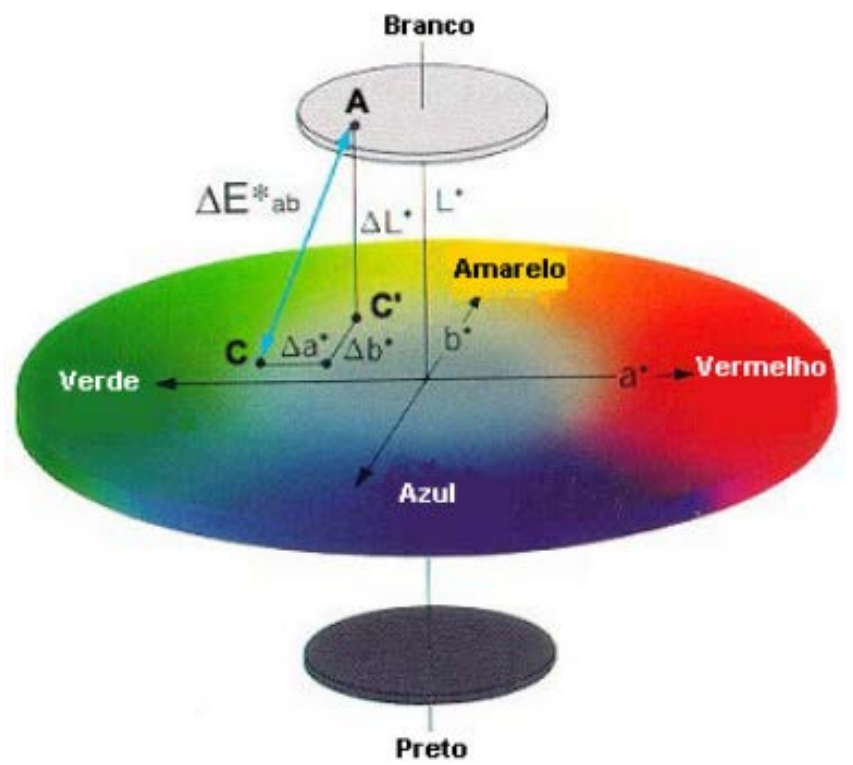

Figura 1 - Significado geométrico das coordenadas a*, b* e L* no diagrama CIELAB (Minolta, 2007).

\section{ANÁLISE PETROGRÁFICA}

As propriedades petrográficas inerentes a cor branca (Figura 4A), equigranular, com cada rocha são posteriormente, e sempre que possível, correlacionadas com os dados tecnológicos visando uma avaliação da influência dos aspectos composicionais, texturais e estruturais no comportamento físico-mecânico e químico das respectivas rochas estudadas.

A síntese das principais características petrográficas das rochas aglomeradas e das naturais é apresentada nas figuras 2 e 3, respectivamente.

\section{Rocha A1} granulação fina $(<1 \mathrm{~mm})$, textura fanerítica e estrutura com cerca de $30 \%$ de grãos em relação à matriz. O estado microfissural é baixo, exibindo cerca de 0,12 microfissuras $/ \mathrm{mm}^{2}$.

É composta mineralogicamente por quartzo (99\%) e muscovita (1\%), está em processo de alteração ou já alterada para minerais de argila. Os grãos de quartzo são anédricos, com microfissuras intragranulares e sem preenchimento (Figura 4B), subarredondados a angulosos, exibindo superfícies de contato com a matriz irregulares (80\%) e planas (20\%).

Corresponde a uma superfície de quartzo de 


\begin{tabular}{|c|c|c|c|c|c|c|c|}
\hline \multicolumn{2}{|c|}{ Características Petrográficas } & \multicolumn{2}{|l|}{ A1 } & \multicolumn{2}{|l|}{ A2 } & \multicolumn{2}{|l|}{ A4 } \\
\hline \multicolumn{2}{|c|}{ Cor } & \multicolumn{2}{|c|}{ Branca } & \multicolumn{2}{|c|}{ Branca } & \multicolumn{2}{|c|}{ Cinza escuro } \\
\hline \multirow{2}{*}{ Estrutura } & Matriz (\%) & \multicolumn{2}{|l|}{70} & \multicolumn{2}{|l|}{70} & \multicolumn{2}{|c|}{75} \\
\hline & Arcabouço (\%) & \multicolumn{2}{|l|}{30} & \multicolumn{2}{|l|}{30} & \multicolumn{2}{|l|}{25} \\
\hline \multicolumn{2}{|c|}{ Granulação relativa } & \multicolumn{2}{|l|}{ Fina } & \multicolumn{2}{|c|}{ Fina a Média } & \multicolumn{2}{|c|}{ Fina a Média } \\
\hline \multirow{2}{*}{ Granulação (mm) } & Variação & \multicolumn{2}{|l|}{0,1 a 1} & \multicolumn{2}{|c|}{0,1 a 3} & \multicolumn{2}{|c|}{0,1 a 5} \\
\hline & Predominância & \multicolumn{2}{|c|}{0,3 a 0,5} & \multicolumn{2}{|c|}{0,4 a 0,7} & \multicolumn{2}{|c|}{1 a 2} \\
\hline \multirow{3}{*}{ Composição (\%) } & Quartzo & \multicolumn{2}{|l|}{99} & \multicolumn{2}{|l|}{77} & \multicolumn{2}{|l|}{87} \\
\hline & $\begin{array}{l}\text { Muscovita/Argilomi } \\
\text { nerais }\end{array}$ & \multicolumn{2}{|l|}{1} & \multicolumn{2}{|l|}{20} & \multicolumn{2}{|l|}{--} \\
\hline & Vidro (espelho) & \multicolumn{2}{|l|}{--} & \multicolumn{2}{|l|}{3} & \multicolumn{2}{|l|}{13} \\
\hline Forma & los grãos & $\begin{array}{r}\begin{array}{r}\text { Subarredond } \\
\text { angulos }\end{array} \\
\end{array}$ & $\begin{array}{l}\text { idos a } \\
\text { s }\end{array}$ & $\begin{array}{r}\text { Subarredonc } \\
\text { angulos }\end{array}$ & ados a & Arredondados a & angulosos \\
\hline & & $\begin{array}{c}\text { Sem } \\
\text { preenchimento }\end{array}$ & $\begin{array}{l}\text { Preenchi } \\
\text { das }\end{array}$ & $\begin{array}{c}\text { Sem } \\
\text { preenchimento }\end{array}$ & $\begin{array}{c}\text { Preenchi } \\
\text { das }\end{array}$ & $\begin{array}{c}\text { Sem } \\
\text { preenchimento }\end{array}$ & $\begin{array}{l}\text { Preenchi } \\
\text { das }\end{array}$ \\
\hline Microfissuras & Intragrão (\%) & 100 & -- & 100 & -- & 100 & -- \\
\hline & Intergrão (\%) & -- & -- & -- & -- & -- & -- \\
\hline Microfis & uras $/ \mathbf{m m}^{2}$ & 0,12 & & 0,10 & & 0,06 & \\
\hline & Serrilhado (\%) & 70 & & 40 & & 15 & \\
\hline Articulação & Côncavo-convexo (\%) & 10 & & -- & & 85 & \\
\hline & Planar (\%) & 20 & & 60 & & -- & \\
\hline
\end{tabular}

Figura 2 - Síntese das propriedades petrográficas das rochas aglomeradas estudadas.

\begin{tabular}{|c|c|c|c|c|c|}
\hline \multicolumn{2}{|c|}{ Características Petrográficas } & \multicolumn{2}{|c|}{ N1 } & \multicolumn{2}{|r|}{ N2 } \\
\hline \multicolumn{2}{|c|}{ Coloração } & \multicolumn{2}{|c|}{ Preta } & \multicolumn{2}{|c|}{ Verde } \\
\hline \multicolumn{2}{|c|}{ Estrutura } & \multicolumn{2}{|c|}{ Isotrópica } & \multicolumn{2}{|c|}{ Anisotrópica } \\
\hline \multicolumn{2}{|l|}{ Textura } & \multicolumn{2}{|c|}{ Granolepidoblástica } & \multicolumn{2}{|c|}{ Granolepidoblástica } \\
\hline \multicolumn{2}{|c|}{ Granulação relativa } & \multicolumn{2}{|c|}{ Fina } & \multicolumn{2}{|c|}{ Fina } \\
\hline \multirow{10}{*}{ 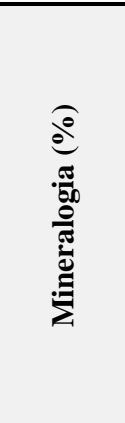 } & Quartzo & \multicolumn{2}{|c|}{76} & \multicolumn{2}{|r|}{94} \\
\hline & Plagioclásio & \multicolumn{2}{|r|}{5} & \multicolumn{2}{|r|}{--} \\
\hline & Biotita & \multicolumn{2}{|c|}{10} & \multicolumn{2}{|r|}{--} \\
\hline & Fuchsita & \multicolumn{2}{|r|}{--} & \multicolumn{2}{|r|}{3} \\
\hline & Opacos & \multicolumn{2}{|r|}{1} & \multicolumn{2}{|r|}{$\operatorname{tr}$} \\
\hline & Zircão & \multicolumn{2}{|r|}{--} & \multicolumn{2}{|r|}{$\operatorname{tr}$} \\
\hline & Sericita/Muscovita & \multicolumn{2}{|r|}{4} & \multicolumn{2}{|r|}{1} \\
\hline & Epidoto & & $\operatorname{tr}$ & & $\operatorname{tr}$ \\
\hline & Clorita & & $\operatorname{tr}$ & & -- \\
\hline & Carbonatos & & 3 & & 1 \\
\hline & Óxido e/ou Hidróxido de ferro & & -- & & 1 \\
\hline & Total máficos (\%) & & 10 & & 1 \\
\hline 코즈 & Variação & & a 0,8 & & a 0,7 \\
\hline 跑氙百 & Predominância & & a 0,5 & & 3 a 0,7 \\
\hline & & Abertas & Preenchidas & Abertas & Preenchidas \\
\hline$\stackrel{\frac{\pi}{3}}{3}$ & Intragrão (\%) & 4 & 1 & - & - \\
\hline$\stackrel{\infty}{0}$ & Intergrão (\%) & 5 & 90 & 5 & 0 \\
\hline 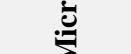 & Transgranular (\%) & - & - & 0 & 95 \\
\hline & Comunicabilidade & & aixa & & Média \\
\hline & licrofissuras $/ \mathbf{m m}^{2}$ & & ,31 & & 0,14 \\
\hline อ न & Lobulado/engrenado & & 80 & & 89 \\
\hline 혈 & Plano & & 15 & & 10 \\
\hline & Côncavo-convexo & & 5 & & 1 \\
\hline & Plagioclásio & & derado & & dsente \\
\hline 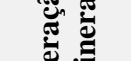 & Biotita & & ipiente & & usente \\
\hline 专之 & Fuchsita & & isente & & ipiente \\
\hline Clas & sificação Petrográfica & $\begin{array}{r}\text { Biotita } \\
\text { I }\end{array}$ & $\begin{array}{l}\text { uartzito com } \\
\text { dspato }\end{array}$ & Fuchsi & a Quartzito \\
\hline
\end{tabular}

Figura 3 - Síntese das propriedades petrográficas das rochas naturais. 

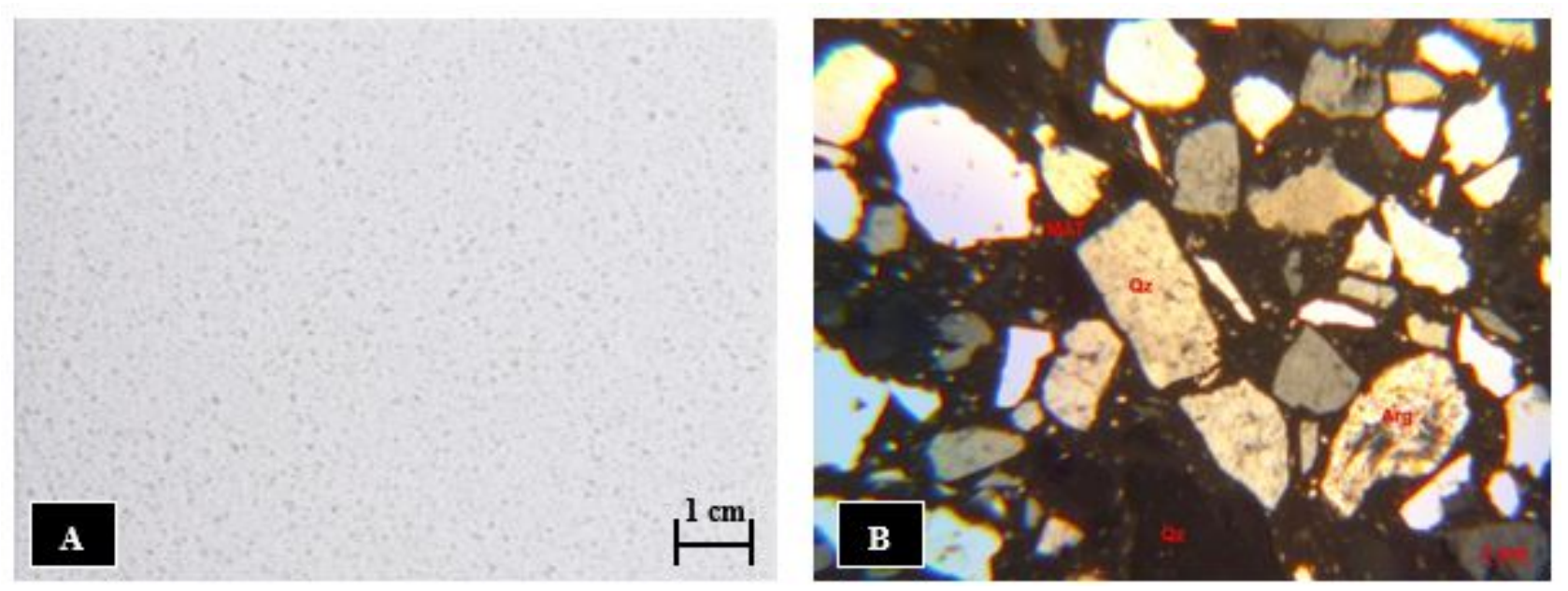

Figura 4 - Rocha aglomerada A1: (A) Aspecto macroscópico e (B) fotomicrografia exibindo grãos de quartzo com contatos irregulares e microfissuras preenchidas por minerais secundários. Polarizadores cruzados e lente objetiva de 2,5x de aumento. Legenda: $\mathbf{Q z}=$ Quartzo, Arg= Argilominerais e MAT= Matriz.

\section{Rocha A2}

Rocha aglomerada de cor branca, inequigranular, com granulação variando de fina $(<1 \mathrm{~mm})$ a média $(1$ a $5 \mathrm{~mm})$ e estrutura com cerca de $30 \%$ de grãos incorporados à matriz afanítica (70\%) (Figura 5A).

Os grãos exibem superfícies de contato planares (60\%) e irregulares (40\%), com imbricamento serrilhado com a matriz. Encontram-se pouco microfissurados, com cerca de 3\% dos grãos apresentando microfissuras intragranulares e sem preenchimento.

Os grãos que compõem o material são quartzo, vidro e argilominerais. Os cristais de quartzo perfazem cerca de $25 \%$ do material, são

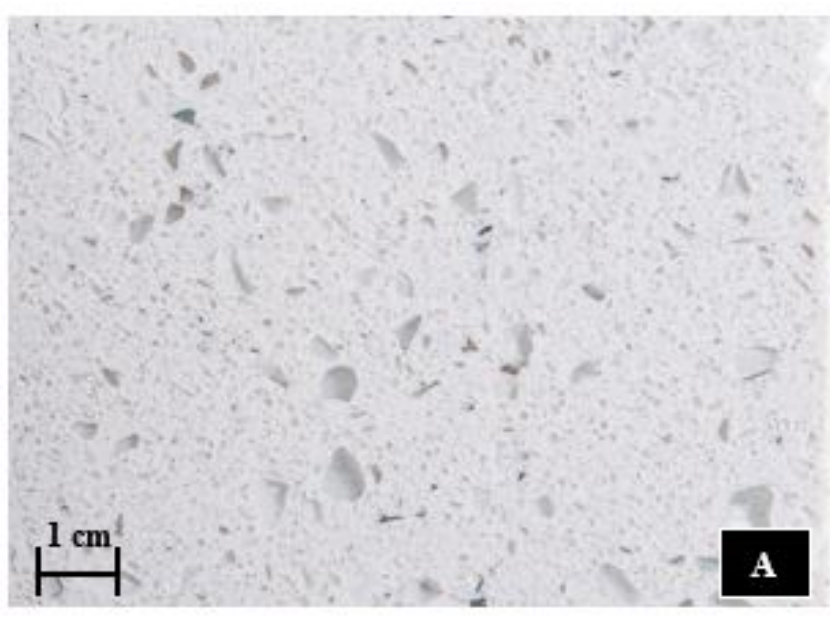

anédricos, com formas subarredondadas a angulosas, possuem granulação variando de fina a média (1 a $3 \mathrm{~mm})$ e superfícies de contato planares e irregulares com imbricamento serrilhado (Figura 5B).

Observa-se uma média de 0,10 microfissuras $/ \mathrm{mm}^{2}$, sendo essas, intracristalinas e sem preenchimento.

Os vidros compõem cerca de 5\% do material, possuem granulação variando de fina a média, alta angulosidade e exibem superfícies de contato planares com a matriz.

Os argilominerais compõem cerca de $1 \%$ do material, são anédricos e estão entre interstícios de grãos de quartzo, bordejando-os..

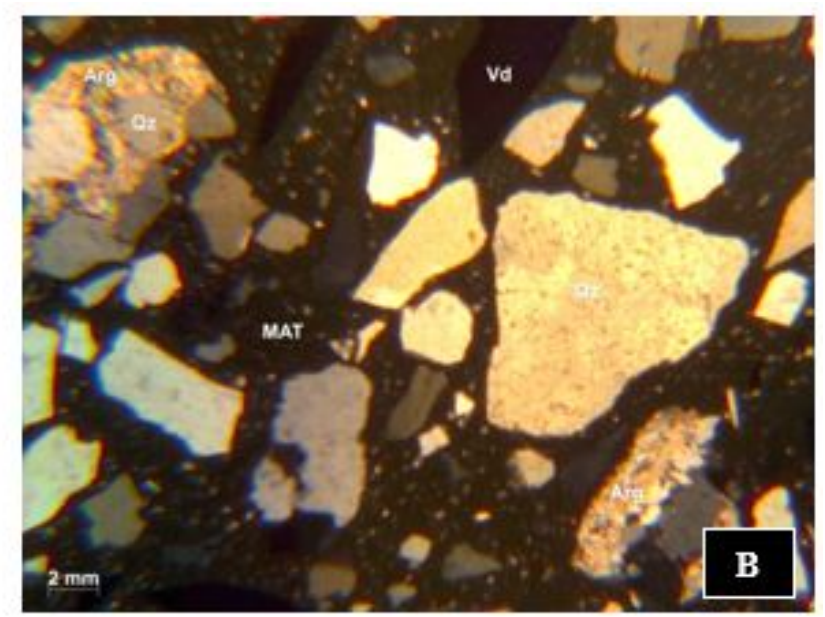

Figura 5 - Rocha aglomerada A2: (A) Aspecto macroscópico e (B) fotomicrografia exibindo textura inequigranular com polarizadores cruzados e lente objetiva de 2,5x de aumento. Legenda: $\mathbf{Q z}=$ Quartzo, Vd= Vidro, Arg= Argilominerais e MAT $=$ Matriz.

\section{Superfície A3}

O material de revestimento A3 corresponde a um produto denominado superfície ultracompacta sinterizada. O método de fabricação emprega tecnologia de ponta para simular os processos geológicos naturais de pressão e temperatura que resultariam em uma rocha metamórfica. O produto final é uma superfície homogênea, de coloração bege e de aspecto vítreo (Figura 6A). Em lâmina 
petrográfica não foi possível identificar nenhum mineral constituinte (Figura 6B).

A mineralogia foi então determinada pela análise de DRX (Figura 7), sendo possível identificar os minerais quartzo, mulita, microclínio, zircão e albita. A composição química identificada pela fluorescência de raios X (Tabela 3) corrobora esse resultado. A ficha técnica de um produto similar do mercado descreve uma composição mineralógica semelhante (Cosentino, 2018)

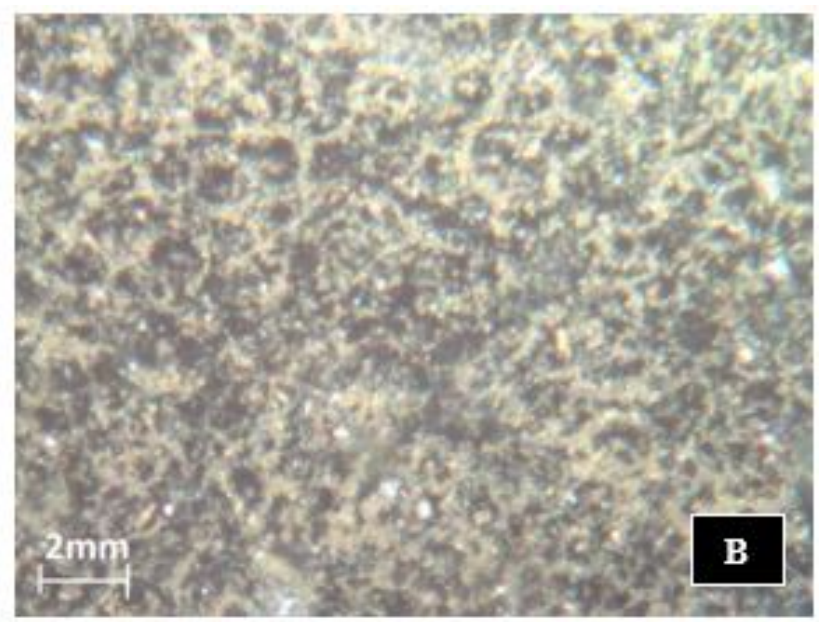

Figura 6 - Superfície ultracompacta denominada A3. (A) Aspecto macroscópico e (B) fotomicrografia com polarizadores cruzados e lente objetiva de 10x aumento.

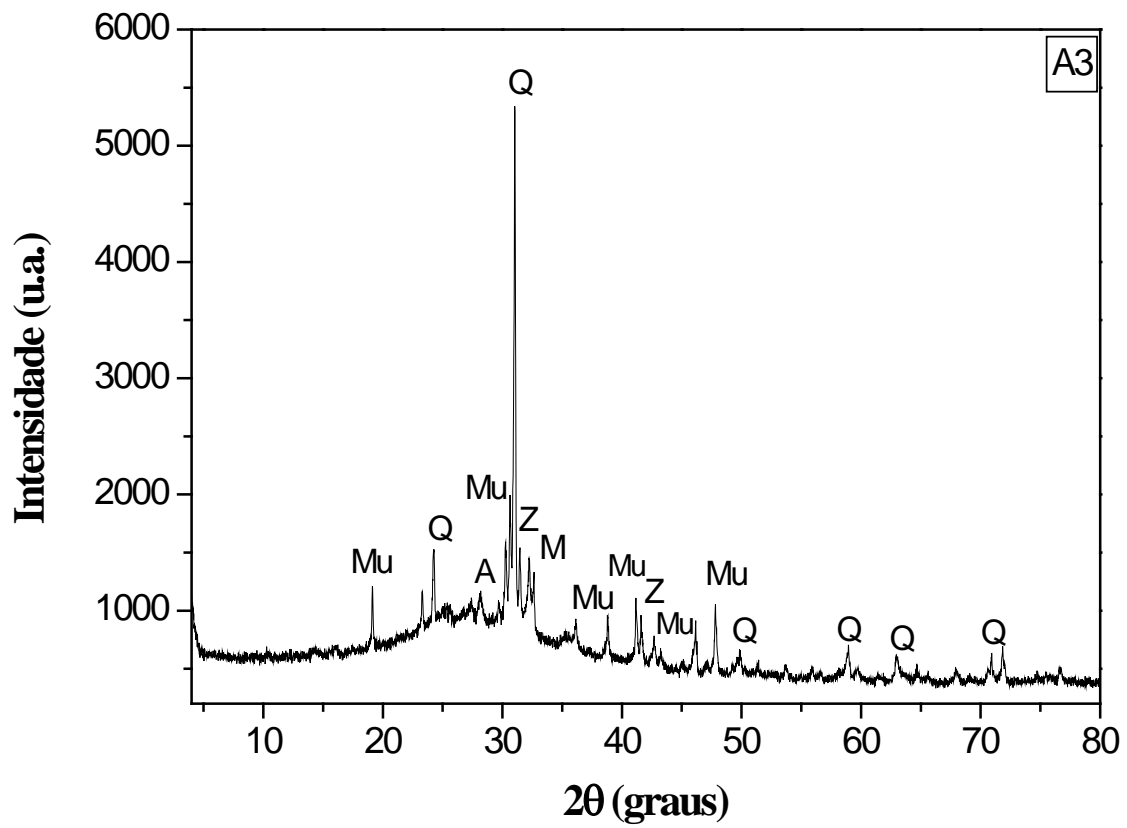

Figura 7 - Difratograma de raios-X da superfície ultracompacta A3. Legenda: $\mathbf{Q}=$ quartzo; $\mathbf{M u = ~ m u l i t a ; ~} \mathbf{M =}$ microclínio; $\mathbf{Z}=$ zircão; $\mathbf{A}=$ albita.

Tabela 3 - Composição química da superfície ultracompacta denominada A3.

\begin{tabular}{c|c|c|c|c|c|c|c|c|c|c|c}
\hline & \multicolumn{10}{c}{ Óxidos } \\
\hline & $\mathbf{S i O}_{2}$ & $\mathbf{A l}_{2} \mathbf{O}_{3}$ & $\mathbf{N a}_{2} \mathbf{O}$ & $\mathbf{K}_{\mathbf{2}} \mathbf{O}$ & $\mathbf{F e}_{2} \mathbf{O}_{3}$ & $\mathrm{ZrO}_{2}$ & $\mathbf{C a O}$ & $\mathbf{M g O}$ & $\mathbf{T i O}_{2}$ & $\mathbf{M n O}$ & PPC $^{*}$ \\
\hline$\%$ & 61,5 & 25,4 & 5,0 & 4,2 & 1,4 & 0,91 & 0,46 & 0,44 & 0,16 & 0,10 & 0,40 \\
\hline
\end{tabular}

*PPC: perda por calcinação

\section{Rocha A4}

Rocha de cor cinza escuro inequigranular, composta por $75 \%$ de matriz quartzosa muito fina e $25 \%$ de grãos (quartzo e vidro) incorporados a ela (Figura 8A), variando a granulação de fina $(<1 \mathrm{~mm})$ a média $(1$ a $5 \mathrm{~mm})$.

Os grãos de quartzo perfazem cerca de $26 \%$ da rocha, possuem granulação fina e encontramse com alto grau de arredondamento (Figura 8B), predominantemente, com alguns grãos subangulosos, exibindo superfícies de contato irregulares, com imbricamento do tipo côncavoconvexo e serrilhado. Raramente são observadas microfissuras intragranulares, cerca de 
$0,06 / \mathrm{mm}^{2}$, e não possuem preenchimento.

Os vidros compõem cerca de $4 \%$ da rocha, possuem granulação predominantemente média, são angulosos e exibem superfícies de contato planares.

\section{Rocha N1}

A rocha corresponde a um Biotita Quartzito com Feldspato de cor preta, equigranular de granulação fina $(<1 \mathrm{~mm})$ e possui textura granolepdoblástica (Figura 9A).

Quanto a forma dos grãos encontra-se anédricos a subédricos. Exibem superfícies de

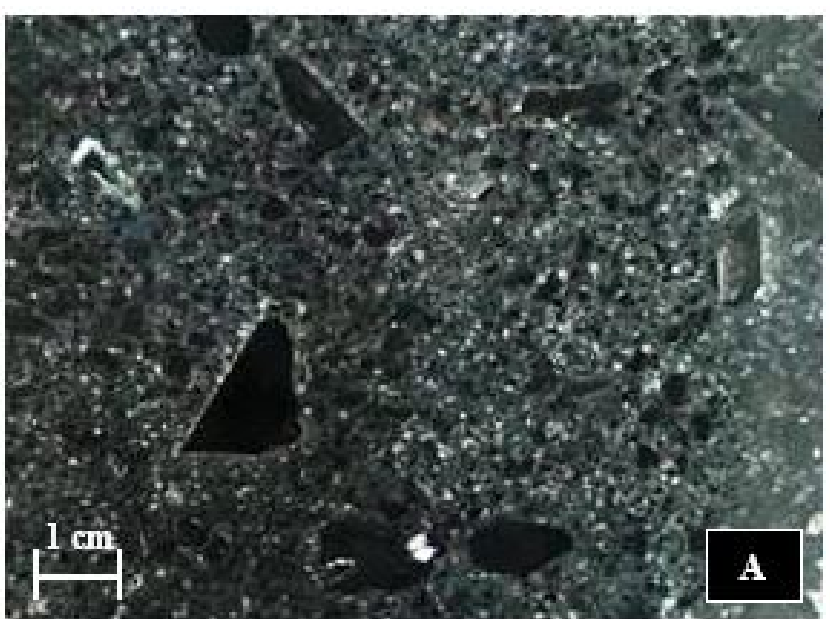

contato irregulares e planares entre os grãos, com predominância de irregulares com imbricamento do tipo serrilhado. Observa-se pontualmente junção tríplice entre grãos de quartzo.

O estado microfissural da rocha é baixo, com aproximadamente 0,31 microfissuras $/ \mathrm{mm}^{2}$, representadas pelos tipos inter e intragranulares, preenchidas ou não por mica branca. O grau de alteração mineral é alto, cerca de $15 \%$ da rocha exibe algum dos processos secundários observados: cloritização, sericitização, saussuritização e carbonatação.

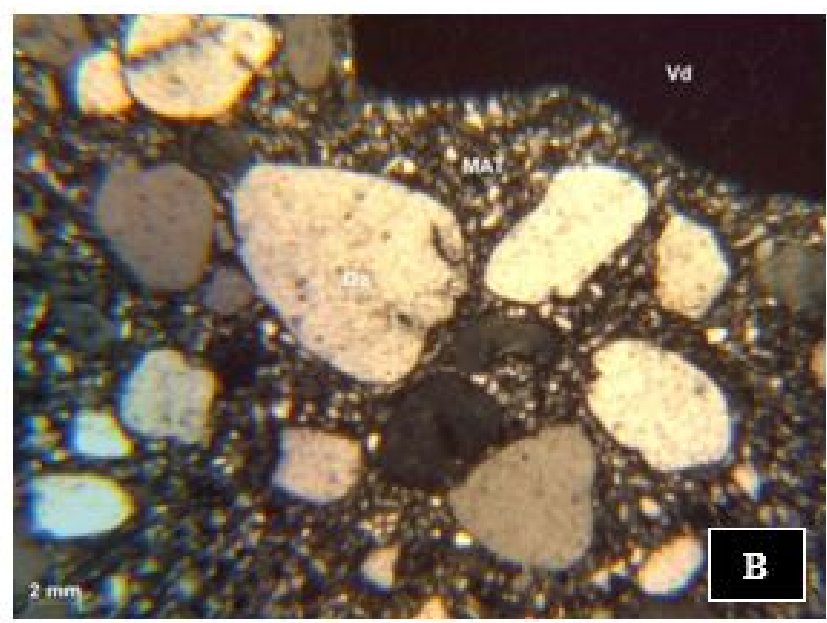

Figura 8 - Rocha aglomerada A4: (A) aspecto macroscópico e (B) fotomicrografia evidenciando cristais de quartzo arredondados com polarizadores cruzados e lente objetiva de 2,5x de aumento. Legenda: Qz= Quartzo, Vd= Vidro e MAT $=$ Matriz.

A rocha é composta principalmente por quartzo, biotita, plagioclásio, muscovita e minerais opacos. Como mineral acessório observa-se epidoto e como minerais secundários clorita, sericita e carbonato. Os cristais de quartzo perfazem cerca de $76 \%$ da rocha, são xenoblásticos, por vezes possuem formas alongadas (Figura 9B), apresentam extinção

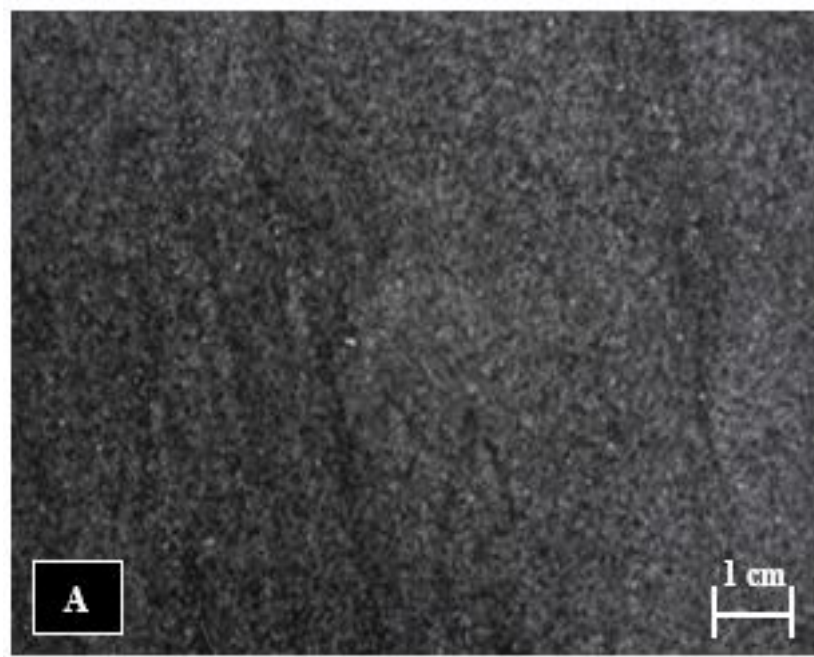

ondulante e alguns possuem microfissuras intracristalinas sem preenchimento.

Os cristais de biotita compõem cerca de 10\% da rocha, são hipidioblásticos a xenoblásticos, possuem hábito lamelar, extinção mosqueada e aproximadamente $30 \%$ dos grãos encontram-se em processo de alteração ou estão totalmente alterados (Figura 9B).

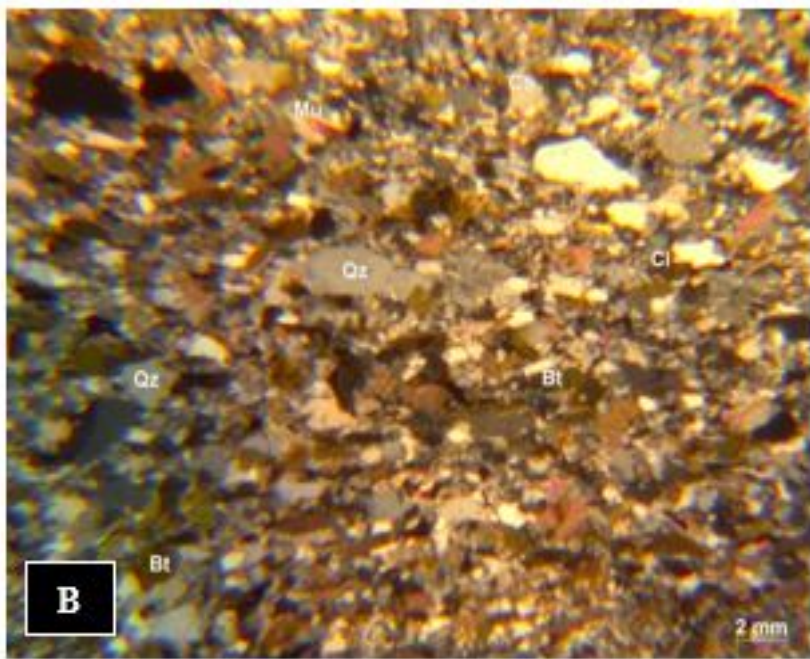

Figura 9 - Biotita Quartzito com Feldspato denominado N1: (A) Aspecto macroscópico e (B) fotomicrografia exibindo leve orientação das micas, quartzo de formato alongado e processos de alteração com polarizadores cruzados e lente objetiva de 5x de aumento. Legenda: $\mathbf{Q z}=$ Quartzo, Bt= Biotita, $\mathbf{M u}=$ Muscovita, $\mathbf{C l}=$ Clorita. 
Possuem microfissuras intragranulares sem preenchimento e exibem superfícies de contato planares, predominantemente, entre os grãos, por vezes irregulares, essas ocorrendo principalmente em grãos que estão em um estágio mais avançado de alteração. Observa-se uma leve orientação dos grãos segundo uma direção preferencial na rocha.

Os cristais de plagioclásio são xenoblásticos, perfazem cerca de $5 \%$ da rocha e estão parciais ou totalmente sericitizados e/ou saussuritizados. É possível visualizar maclas polissintéticas mascaradas pelo intenso estágio de alteração. Observam-se microfissuras intragranulares sem e com preenchimento e os grãos exibem superfícies de contato irregulares, com imbricamento do tipo serrilhado.

Os cristais de muscovita perfazem cerca de $4 \%$ da rocha, são hipidioblásticos a xenoblásticos, possuem hábito lamelar e formas alongadas e finas, cores de interferência altas e exibem contatos planares entre os grãos.

Os cristais de carbonato perfazem cerca de 3\% da rocha e estão associados aos pseudomorfos de plagioclásio. São xenoblásticos, exibem superfícies de contato irregulares entre os grãos, com imbricamento do tipo serrilhado. Em alguns grãos é possível observar estrias/maclas pertencentes aos grãos originais.

Os cristais de clorita compõem cerca de $1 \%$ da

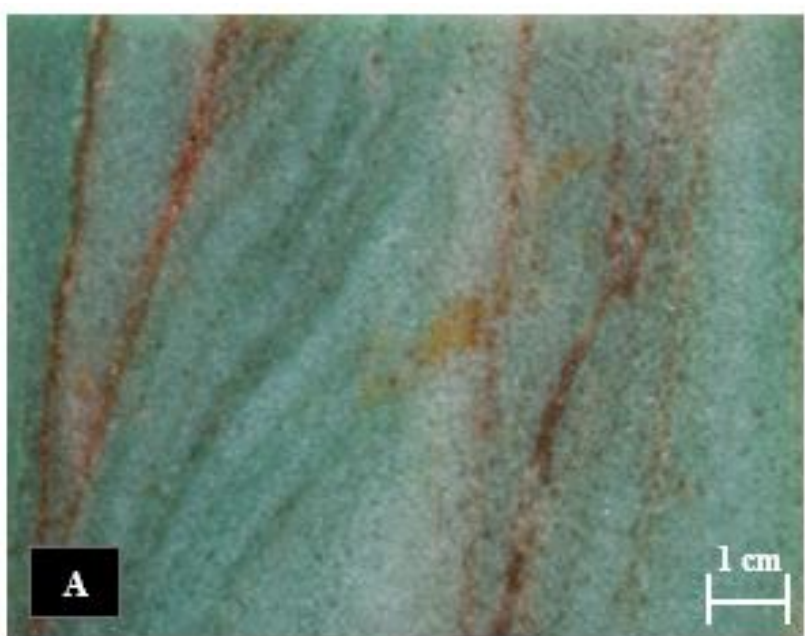

rocha, são produtos de alteração de biotitas e apresentam-se xenoblásticos, quanto ao grau de perfeição dos grãos. Os minerais opacos compõem cerca de $1 \%$ da rocha, são xenoblásticos e sua maioria é produto de alteração de biotitas. Os cristais de epidoto compõem menos de $1 \%$ da rocha, xenoblásticos e exibem superfícies de contato planares.

\section{Rocha N2}

A rocha refere-se a um Fuchsita Quartzito de coloração esverdeada com finos veios amarronzados (Figura 8A). É equigranular, com granulação fina $(<1 \mathrm{~mm})$, possui textura granolepidoblástica e orientação das micas segundo uma direção preferencial. Quanto ao grau de cristalinidade das faces, encontram-se predominantemente xenoblásticos.

Os grãos exibem superfícies de contato irregulares entre si, predominantemente, com imbricamento do tipo serrilhado e poucos contatos planares. O grau de microfissuramento da rocha é baixo $\left(0,14 / \mathrm{mm}^{2}\right)$, com fissuras transgranulares e intergranulares.

Os fissuramentos transgranulares encontramse preenchidos por argilominerais e óxido e/ou hidróxido de ferro, possuem espessuras de até 0,3 $\mathrm{mm}$ e cortam a rocha quase que ortogonalmente à direção de orientação das micas (Figura 10B). As microfissuras intergranulares não possuem preenchimento.



Figura 10 - Fuchsita quartizito denominado N2: (A) Aspecto macroscópico e (B) fotomicrografia exibindo cristais orientados de fuchsita, microfissura transgranular e óxidos/hidróxidos de ferro com polarizadores cruzados e lente objetiva de 5x de aumento. Legenda: $\mathbf{Q z}=$ Quartzo, Fu= Fuchsita, Óx. Fe = Óxido de Ferro.

Ocorrem poucas alterações minerais, cerca de $2 \%$, sendo visíveis principalmente próximas as superfícies fraturadas. Os minerais constituintes da rocha são quartzo, fuchsita (mica verde) e como mineral acessório, epidoto. Observam-se materiais secundários, bem como argilominerais e óxido e/ou hidróxido de ferro. Os cristais de quartzo perfazem cerca de $94 \%$ da rocha, são xenoblásticos, possuem granulação muito fina e extinção ondulante. Exibem contatos irregulares e planares entre os grãos e possuem microfissuras inter e transgranulares. Os cristais de fuchsita 
(Figura 10B) perfazem cerca de 3\% da rocha, são xenoblásticos a hipidioblásticos, possuem pleocroísmo azul a esverdeado, granulação muito fina, estão orientados segundo uma direção preferencial e alguns grãos encontram-se em processo de alteração ou totalmente alterados para argilominerais. Os cristais de epidoto (< 1\%) possuem granulação muito fina, relevo alto e são xenoblásticos quanto ao grau de perfeição dos grãos. Os argilominerais e óxidos e/ou hidróxidos de ferro constituem cerca de $2 \%$ da rocha e encontram-se preenchendo microfissuras.

\section{RESULTADOS DOS ENSAIOS TECNOLÓGICOS E DISCUSSÕES}

A tabela 4 apresenta a síntese dos ensaios de índices físicos e resistência à flexão para as rochas estudadas. Sempre que possível esses resultados são correlacionados com as propriedades petrográficas de cada material e com os valores referenciais para a especificação de quartzitos estabelecidos pela norma C616 (ASTM, 2015), conforme apresentado na tabela 5. As rochas aglomeradas ainda não dispõem de norma de especificação.

Tabela 4 - Síntese dos ensaios físico-mecânicos para as seis rochas estudadas.

\begin{tabular}{c|c|c|c|c}
\hline \multirow{2}{*}{} & \multicolumn{4}{|c}{ Ensaios Tecnológicos } \\
\cline { 2 - 5 } & $\begin{array}{c}\text { Densidade } \\
\text { aparente } \\
\left(\mathrm{kg} / \mathrm{m}^{3}\right)\end{array}$ & $\begin{array}{c}\text { Absorção } \\
\text { d’água } \\
(\%)\end{array}$ & $\begin{array}{c}\text { Porosidade } \\
(\%)\end{array}$ & $\begin{array}{c}\text { Resistência } \\
\text { à Flexão } \\
(\mathrm{MPa})\end{array}$ \\
\hline \multirow{2}{*}{ A1 } & $\begin{array}{c}2409 \pm \\
0,89\end{array}$ & $\begin{array}{c}0,03 \pm \\
0,01\end{array}$ & $\begin{array}{c}0,08 \pm \\
0,01\end{array}$ & $49,9 \pm 3,16$ \\
\hline \multirow{2}{*}{ A2 } & $2375 \pm$ & $0,04 \pm$ & $0,09 \pm$ & $39,9 \pm 2,17$ \\
\hline \multirow{2}{*}{ A3 } & 1,37 & 0,03 & 0,07 & $0,36 \pm$ \\
\hline \multirow{2}{*}{ A4 } & $2343 \pm$ & $0,15 \pm$ & 0,05 & $30,2 \pm 2,32$ \\
\hline \multirow{2}{*}{$\mathbf{N 1}$} & 2,50 & 0,02 & $0,05 \pm$ \\
& 2,42 & 0,02 & 0,05 & $38,0 \pm 2,97$ \\
\hline \multirow{2}{*}{$\mathbf{N 2}$} & 2,53 & $\begin{array}{c}0,21 \pm \\
0,03\end{array}$ & $\begin{array}{c}0,58 \pm \\
0,08\end{array}$ & $39,5 \pm 1,03$ \\
\hline
\end{tabular}

Tabela 5 - Valores requeridos para a especificação de quartzitos conforme a C616 (ASTM, 2015).

\begin{tabular}{l|c}
\hline Propriedade & $\begin{array}{c}\text { Valor } \\
\text { referência }\end{array}$ \\
\hline Densidade, valor mínimo $\left(\mathrm{kg} / \mathrm{m}^{3}\right)$ & 2560 \\
\hline Absorção d’água, valor máximo $(\%)$ & 1 \\
\hline $\begin{array}{l}\text { Módulo de ruptura, valor mínimo } \\
(\mathrm{MPa})\end{array}$ & 13,8 \\
\hline
\end{tabular}

\section{Determinação da Densidade Aparente, Absorção d'água e Porosidade}

Dentre as rochas estudadas, o quartzito N1 apresentou a maior densidade aparente (2.713 $\left.\mathrm{kg} / \mathrm{m}^{3}\right)$, seguido pelo quartzito $\mathrm{N} 2\left(2.639 \mathrm{~kg} / \mathrm{m}^{3}\right)$. Esses valores são bem superiores ao requerido pela C616 (ASTM, 2015) para a especificação de quartzitos, e relacionam-se com o teor de máficos presente na composição dessas rochas de 10 e $7 \%$, respectivamente.

Entre as rochas aglomeradas, a de maior densidade é o tipo A1, rocha que apresenta uma granulometria fina, constituída por $99 \%$ de quartzo, enquanto a superfície sinterizada A3 apresentou o menor valor $\left(2.343 \mathrm{~kg} / \mathrm{m}^{3}\right)$. De forma geral, os materiais artificiais são menos densos porque não possuem a variedade de minerais constituintes de uma rocha natural, nem passaram por processos geológicos que alteram seus minerais, causando microfissuramentos e abertura de poros, que diminuem a densidade. Outro fator é que o elemento ligante dos aglomerados é uma resina orgânica, bem menos densa (1100 a $\left.1200 \mathrm{~kg} / \mathrm{m}^{3}\right)$ que as matrizes das rochas naturais constituídas por silicatos, carbonatos, óxidos e hidróxido de ferro e etc.

A densidade aparente também é correlacionada com a porosidade na figura 11 . Embora seja a rocha mais densa, o tipo N1 também apresentou a maior porosidade (0,5\%). De acordo com a análise petrográfica, essa rocha apresenta grau de alteração mineral alto (cerca de $15 \%$ ), fator que resulta no aumento da porosidade (Tugrul, 2004; Ondrášik \& Kopecky, 2014).

Por sua vez, embora A3 seja um material quase vítreo, a porosidade encontrada $(0,3 \%)$ foi maior do que a da rocha natural N2 $(0,2 \%)$. Ao contrário da superfície polida, o tardoz do tipo A3 apresenta alta rugosidade, e, portanto, maior área de contato, o que permite inferir que seja esse o fator responsável pelo valor de porosidade encontrado. As rochas aglomeradas A1, A2 e A4 apresentam valores de porosidade bastante baixos (0,08\%, 0,09\% e $0,1 \%$, respectivamente), inversamente proporcionais à sua densidade.

A absorção d'água, por sua vez, está diretamente relacionada à porosidade, conforme ilustrado na figura 12.

Coerentemente, o quartzito N1 por ser detentor da maior porosidade, é também a rocha com maior percentual de absorção (0,21\%), seguida pela superfície sinterizada A3 com $0,15 \%$. O quartzito N2 apresentou baixo valor de absorção d'agua (0,09\%), mesmo com índice de porosidade relativamente alto. 


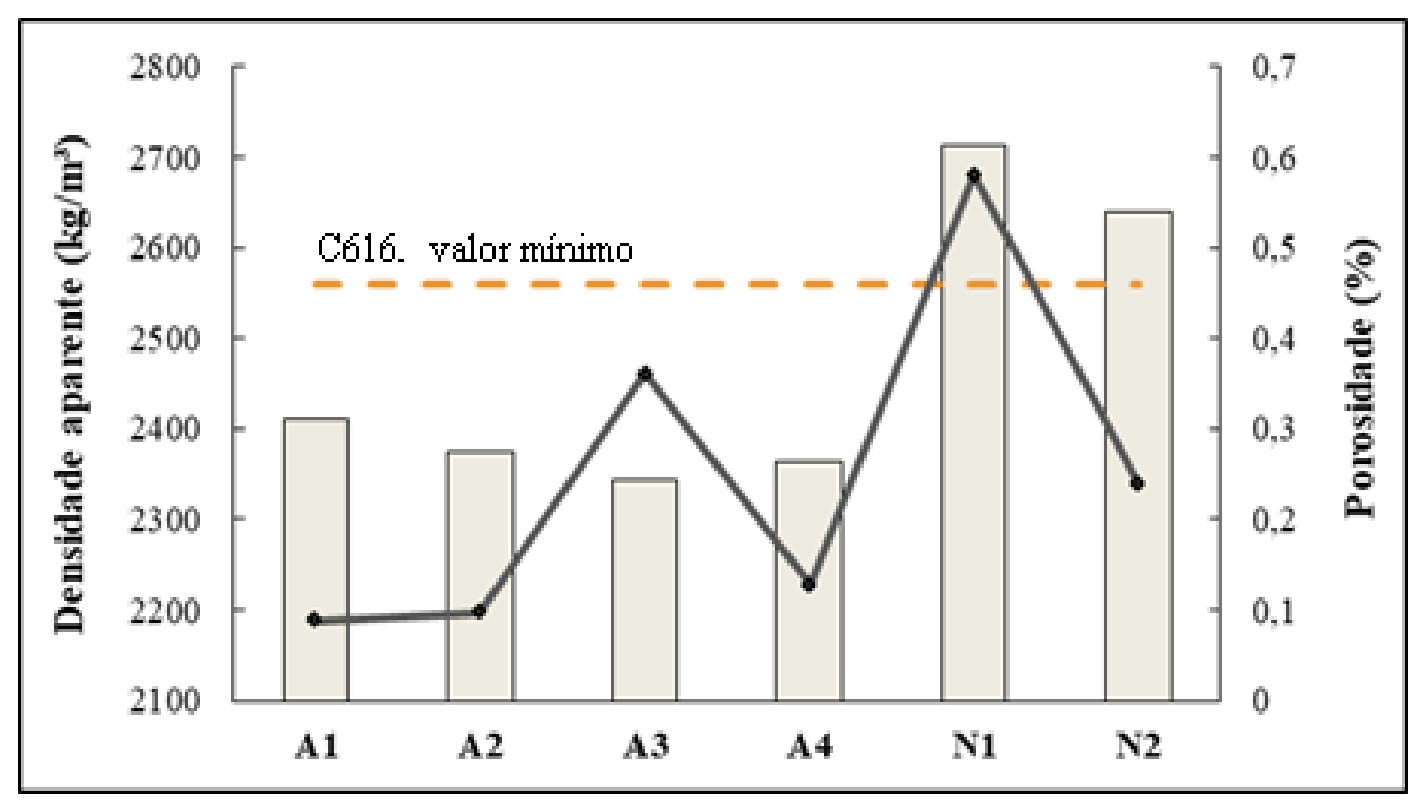

Figura 11 - Correlação entre densidade aparente (colunas) e porosidade (linha cheia) das rochas estudadas. A linha tracejada laranja representa o valor mínimo de densidade estabelecido pela C616 (ASTM, 2015) para a especificação de quartzitos.

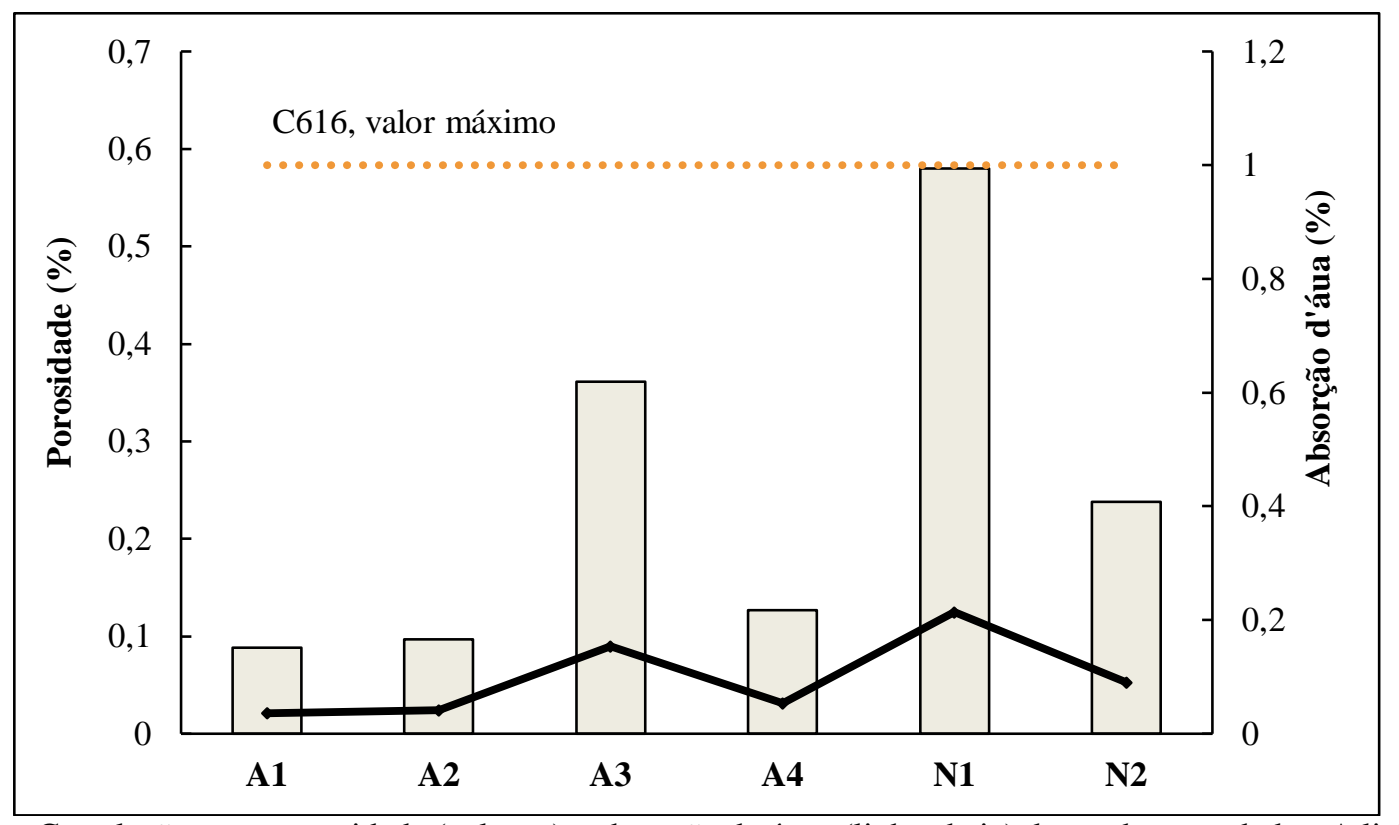

Figura 12 - Correlação entre porosidade (colunas) e absorção de água (linha cheia) das rochas estudadas. A linha laranja representa o valor máximo de absorção d’água estabelecido pela C616 (ASTM, 2015) para a especificação de quartzitos.

Esse desempenho deve-se à sua granulação fina, com predominância de grãos entre 0,2 e $0,7 \mathrm{~mm}$, ao grau de alteração incipiente e às suas microfissuras que encontram-se 95\% preenchidas. Tanto N1 quanto N2 atendem com ampla margem a especificação da norma C616 (ASTM, 2015) quanto ao valor máximo para absorção d’água.

A rocha aglomerada A1 apresentou o menor valor para a absorção d'água $(0,03 \%)$, seguida dos tipos A2 (0,04\%) e A4 (0,05\%), o que está relacionado à homogeneidade do material, caracterizado por sua estrutura isotrópica, textura equigranular fina com predominância de grãos entre 0,3 e $0,5 \mathrm{~mm}$ e excelente imbricamento mineral.

\section{Determinação da Resistência à Flexão}

A figura 13 ilustra os resultados do ensaio de resistência à flexão. Com exceção do quartzito N2, cujo desempenho mecânico foi de 25,4 MPa, todas as rochas estudadas apresentaram valores de resistência acima de $30 \mathrm{MPa}$. O valor mínimo de resistência à flexão para a especificação de quartzitos sugerido pela C616 (ASTM, 2015) é de 13,8 MPa, o que foi superado com ampla margem por ambas rochas naturais.

As principais propriedades petrográficas que influenciam no bom desempenho mecânico 
diante das solicitações fletoras ou compressivas são a estrutura, a textura e o tipo de entrelaçamento mineral (Sousa, 2013; Fener \& Ince, 2012; Török \& Vásárhelyi, 2010). Assim, o tipo N2 por ser o único detentor de estrutura anisotrópica, cuja orientação preferencial das micas configura planos de fraqueza, corrobora sua menor resistência relativa.

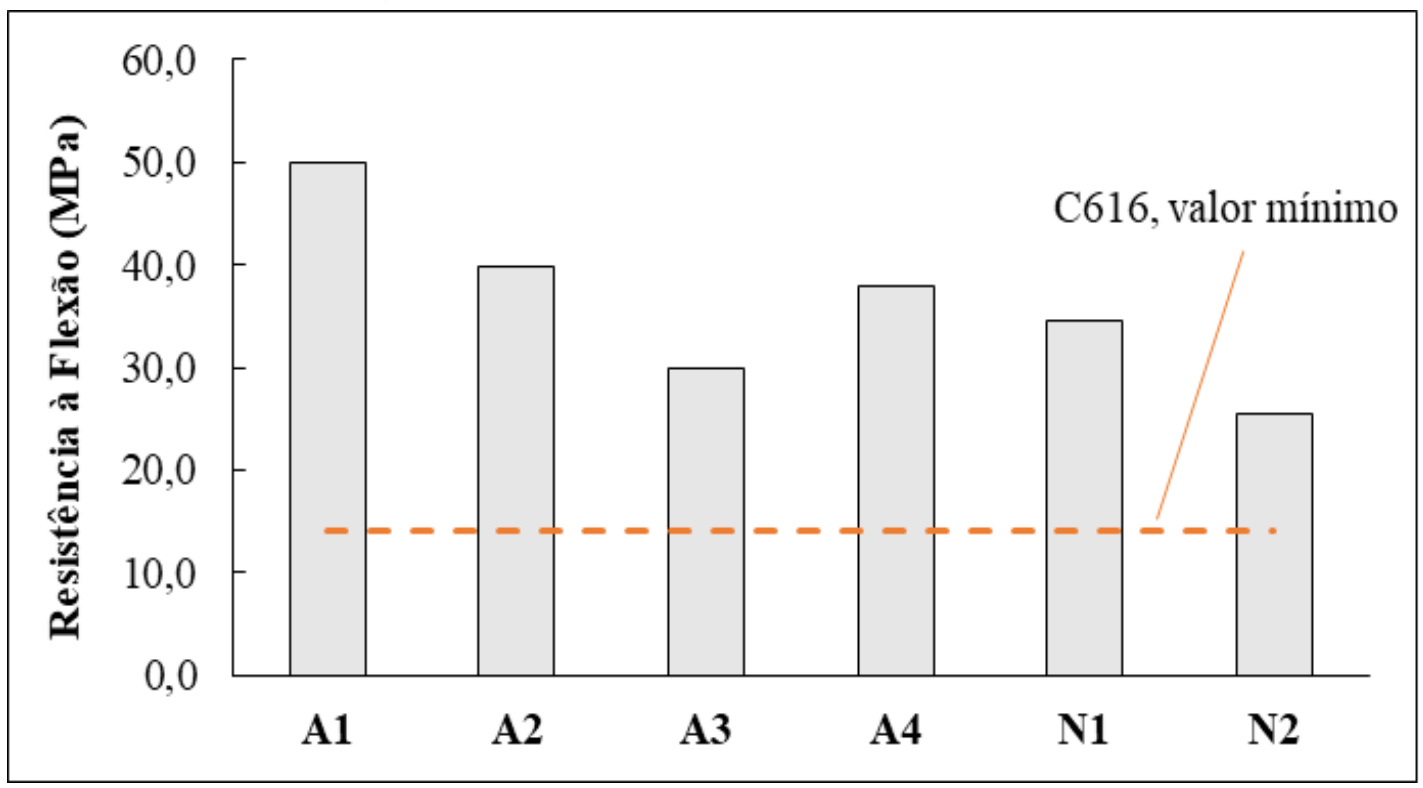

Figura 13 - Resistência à flexão das rochas estudadas. A linha laranja representa o valor mínimo de resistência estabelecido pela C616 (ASTM, 2015) para a especificação de quartzitos.

Dentre as rochas aglomeradas, o melhor desem-penho foi apresentado pelo tipo A1 (49,9 MPa).

Esse comportamento está diretamente relacionado às propriedades petrográficas do material, que é isotrópico e possui textura equigranular fina, além do forte entrelaçamento mineral com a matriz do tipo serrilhado.

Os tipos A2 e A4 obtiveram desempenho semelhante (39,9 e 38,0 MPa, respectivamente), já que ambas apresentam textura inequigranular e contatos minerais do tipo planar e concavoconvexo, menos entrelaçados com a matriz que os do tipo A1. Já a superfície ultracompacta A3, com $30 \mathrm{MPa}$, obteve desempenho inferior ao quartzito N1.

Por ser um material sinterizado, infere-se que o tratamento térmico torna o material mais rúptil, com contatos entre grãos predominantemente planos, o que diminui sua resistência diante de esforços fletores.

É necessário um estudo microestrutural aprofundado a fim de interpretar apropriadamente o comportamento mecânico da superfície A3.

\section{Determinação da Resistência Química}

Na tabela 6 encontram-se os valores para a variação de brilho das rochas estudadas, enquanto a figura 14 ilustra esse parâmetro.
A figura 15 apresenta as características visuais das amostras após serem expostas aos reagentes químicos por oito horas. De maneira geral, o hidróxido de sódio $(\mathrm{NaOH})$ altera mais as características das rochas estudadas do que o ácido clorídrico $(\mathrm{HCl})$, o que pode estar relacionado à capacidade reativa dessa base com os minerais de natureza ácida (silicatos) que as compõe (Simão, 2003).

Tabela 6 - Variação de brilho ocasionada pelos reagentes químicos na superfície das rochas estudadas.

\begin{tabular}{c|c|c|c|c|c|c}
\hline & \multicolumn{3}{|c|}{ HCI } & \multicolumn{3}{c}{ NaOH } \\
\cline { 2 - 7 } & $\mathbf{B I}$ & $\mathbf{B F}$ & $\mathbf{\% \Delta \mathbf { B }}$ & $\mathbf{B I}$ & $\mathbf{B F}$ & $\mathbf{\%} \mathbf{\Delta B}$ \\
\hline A1 & 55,6 & 51,10 & $-8,1$ & 58,88 & 31,36 & $-46,7$ \\
\hline A2 & 44,96 & 39,84 & $-11,4$ & 48,54 & 30,96 & $-36,2$ \\
\hline A3 & 73,58 & 70,62 & $-4,0$ & 72,3 & 62,2 & $-13,9$ \\
\hline A4 & 49,96 & 47,7 & $-4,5$ & 48,52 & 36,38 & $-25,0$ \\
\hline N1 & 58,86 & 55,92 & $-4,9$ & 68,52 & 38,7 & $-43,5$ \\
\hline N2 & 67,98 & 66,38 & $-2,4$ & 68,72 & 60,58 & $-11,9$ \\
\hline
\end{tabular}

BI - Brilho inicial, BF - Brilho Final, \% $\mathbf{\Delta B}$ - Variação de brilho.

Mesmo não demonstrando visualmente a alteração das características estéticas, devido à coloração clara (Figura 15), as superfícies de quartzo A1 e A2 foram os materiais que apresentaram perda de brilho mais significativa (46 e 36\%, respectivamente), o que pode estar relacionado à remoção de partículas do polímero de suas matrizes e também ao pigmento orgânico 
que dá sua coloração branca característica.

dada da solução pós ensaio a fim de determinar

Seria necessária uma análise mais aprofun- precisamente quais foram os íons removidos.

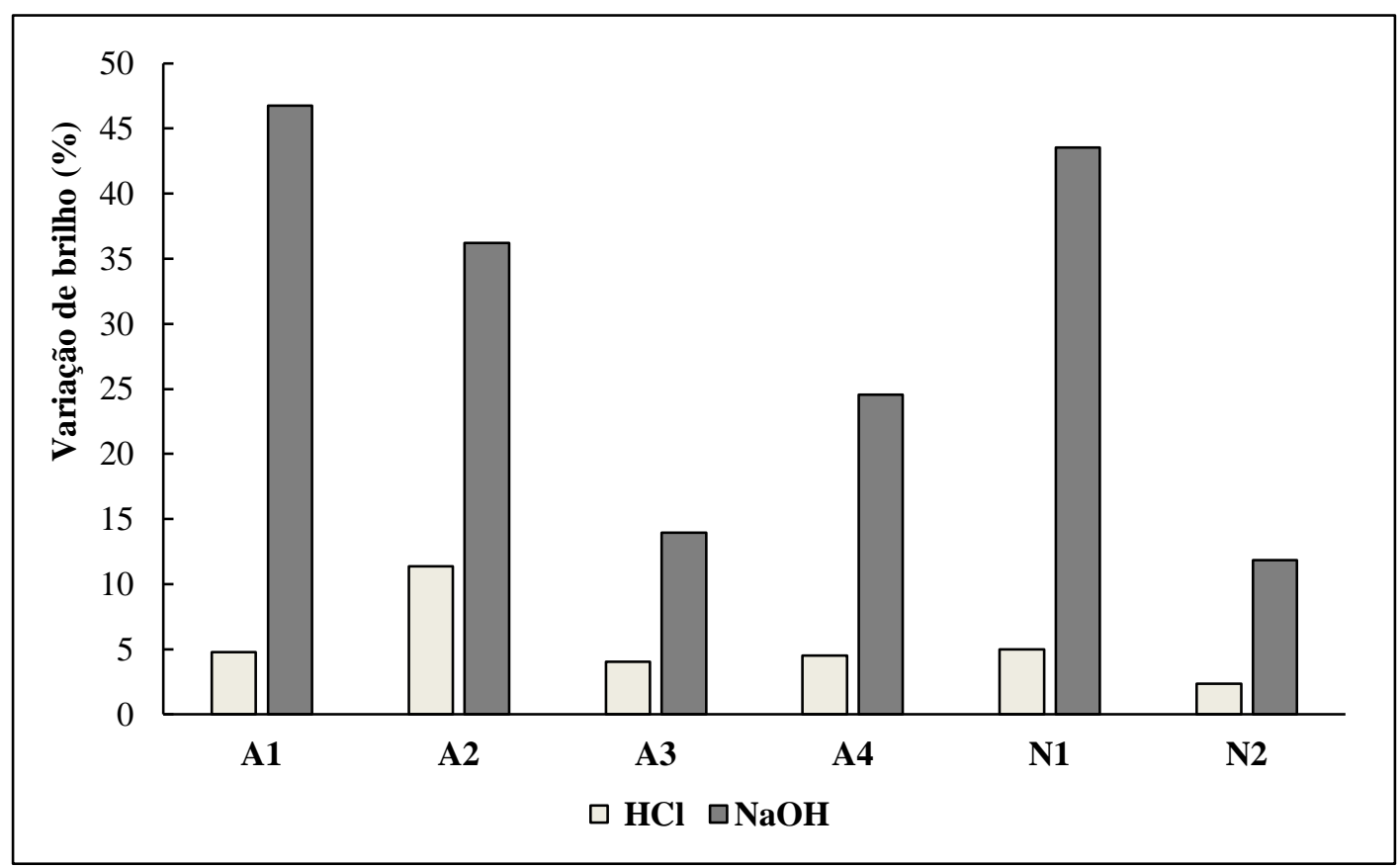

Figura 14 - Variação de brilho das rochas estudadas após ensaio de resistência química.

Quanto ao aspecto visual, coerentemente as rochas de coloração escura, sejam naturais ou artificiais apresentaram maior descaracterização estética, tanto para o ácido clorídrico, quanto para o hidróxido de sódio.

No caso do quartzito N1 (perda de brilho de 43,5\%), o elevado grau de alteração de seus constituintes máficos facilita a remoção dos íons de ferro, clareando o material. O branqueamento da superfície de quartzo A4 está relacionado à remoção do pigmento preto que dá sua coloração.

Por sua vez, o quartzito verde N2 apresentou a menor variação de brilho para os dois reagentes, com leve perda de coloração (Figura 15). Sua textura fina, baixa porosidade $(0,2 \%)$ e composição mineral dada por $95 \%$ de quartzo fazem com que essa rocha seja bastante resistente à ação dos reagentes estudados.

\section{Determinação da Resistência ao Manchamento}

A figura 16 ilustra o aspecto visual das rochas após contato com os agentes manchantes, enquanto na tabela 7 são apresentados os valores de brilho e cor obtidos com o espectrofotômetro. As fotos em alta qualidade podem ser acessadas no link: http://bit.ly/2IkPmk8.

Embora em maior ou menor escala, de maneira geral tanto os materiais artificiais quanto as rochas naturais apresentaram descaracterização de cor e brilho após o ensaio de manchamento. O azeite é o produto do cotidiano que causou perdas de brilho $(\Delta B \%)$ mais pronunciadas (Tabela 7), seguido do desinfetante e do molho de tomate.

Quanto à variação de cor $(\Delta E)$, a norma DIN ISO 11664-4 (Deutsche Institut für Normung, 2019) classifica como distinguíveis a olho nu valores entre 1,6 e 3, facilmente distinguíveis os valores entre 4 e 6 e variações muito grandes os valores maiores que 6 .

De acordo com essa classificação, a superfície de quartzo A4 e o quartzito N2 foram as únicas rochas que apresentaram variações colorimétricas perceptíveis para todos os agentes manchantes, bem como variações significativas de brilho. No entanto, a observação da figura 16 permite visualizar com clareza apenas a ação do azeite e do desinfetante.

A superfície sinterizada A3 apresentou variação de cor distinguível para o café e para o desinfetante, enquanto o quartzito N1 foi manchado apenas pelo azeite (aspecto de umidade permanente). Para este útimo material, a porosidade $(0,58 \%)$ é o fator que mais influencia no espalhamento do líquido e a coloração escura destaca o efeito deletério.

As superfícies de quartzo A1 e A2 são as mais resistentes ao manchamento, não apresentando alteração de cor significativa para nenhum dos agentes $(\Delta E<1,6)$, enquanto às variações de brilho, embora consideráveis, são disfarçadas pela cor clara desses materiais, tornando-as imperceptíveis ao olho nu. 


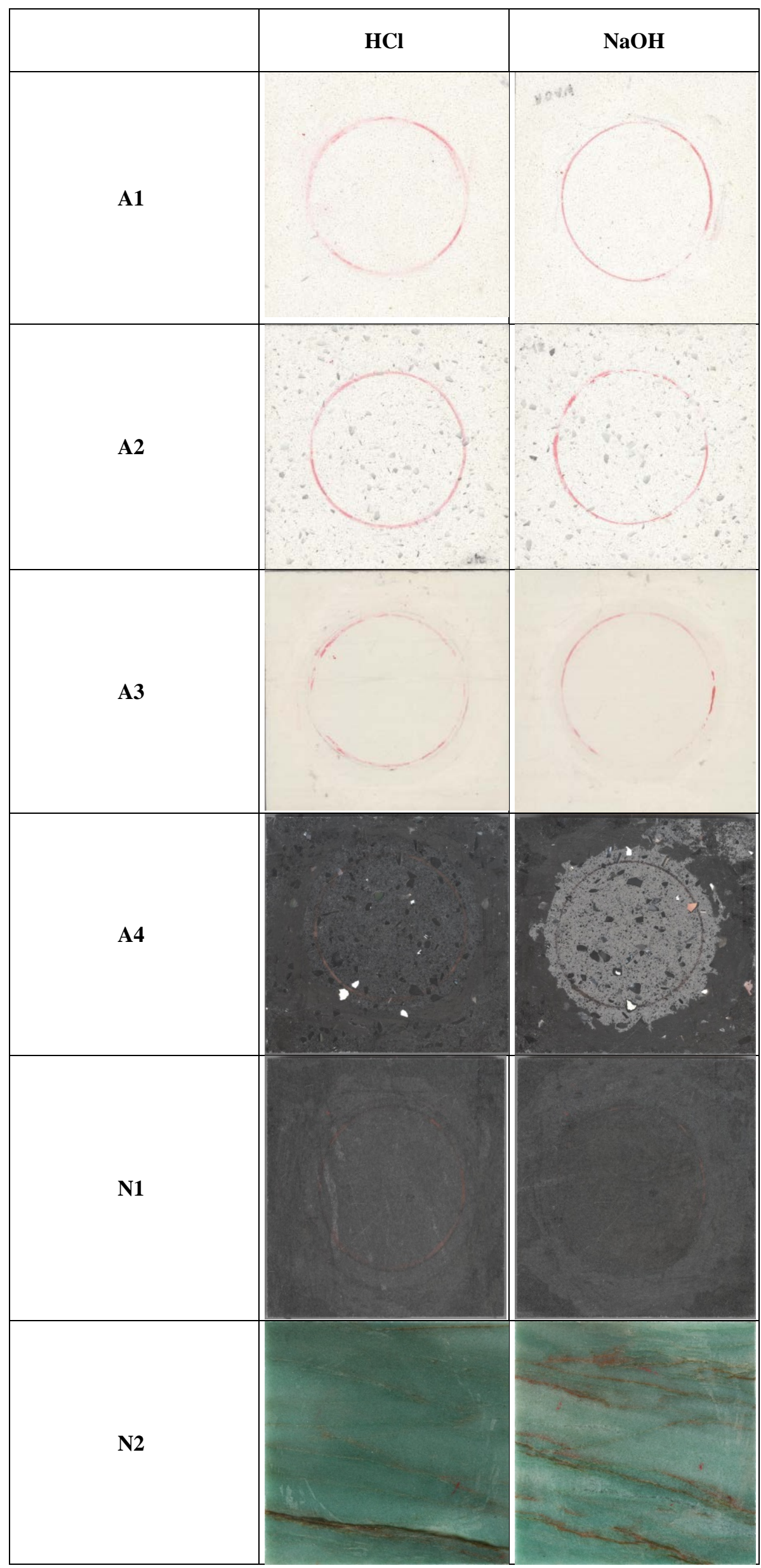

Figura 15 - Aspecto visual das rochas estudadas após contato com os reagentes do ensaio de resistência química. 


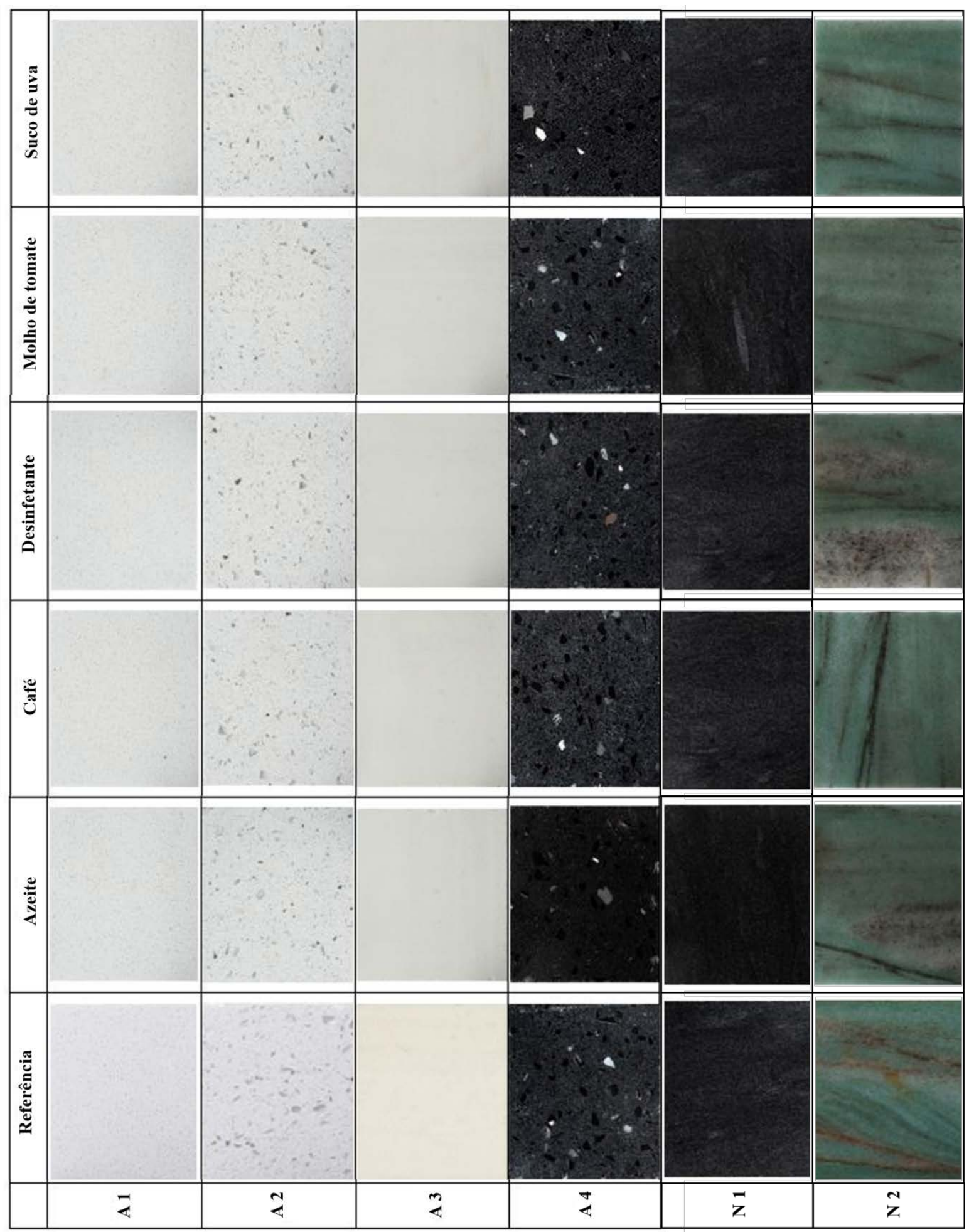

Figura 16 - Aspecto visual das rochas aglomeradas após exposição aos agentes domésticos do ensaio de manchamento.

Tabela 7 - Alteração de brilho e cor devido ao manchamento por agentes domésticos. BI - Brilho inicial, BF - Brilho Final, $\% \Delta \mathbf{B}$ - Porcentagem de variação de brilho e $\boldsymbol{\Delta E}$ - Variação de cores

\begin{tabular}{|c|c|c|c|c|c|c|c|c|c|c|c|c|c|c|c|c|c|c|c|c|}
\hline & \multicolumn{20}{|c|}{ Agentes domésticos } \\
\hline & \multicolumn{4}{|c|}{ Azeite } & \multicolumn{4}{|c|}{ Café } & \multicolumn{4}{|c|}{ Desinfetante } & \multicolumn{4}{|c|}{ Molho de tomate } & \multicolumn{4}{|c|}{ Suco de uva } \\
\hline & BI & $\mathrm{BF}$ & $\% \Delta \mathrm{B}$ & $\Delta E$ & BI & $\mathrm{BF}$ & $\% \Delta B$ & $\Delta E$ & BI & $\mathrm{BF}$ & $\% \Delta B$ & $\Delta E$ & BI & $\mathrm{BF}$ & $\% \Delta B$ & $\Delta E$ & BI & $\mathrm{BF}$ & $\% \Delta B$ & $\Delta E$ \\
\hline Al & 57,5 & 39,7 & $-31,0$ & 0,6 & 57,5 & 57,0 & $-0,9$ & 0,7 & 57,5 & 52,8 & $-8,2$ & 0,2 & 57,5 & 57,0 & $-0,9$ & 0,1 & 57,5 & 50,4 & $-12,3$ & 0,2 \\
\hline A2 & 54,9 & 52,2 & $-4,9$ & 0,4 & 54,9 & 52,2 & $-4,9$ & 0,2 & 52,2 & 50,4 & $-3,4$ & 0,2 & 52,2 & 46,0 & $-11,9$ & 0,5 & 52,2 & 55,7 & 6,7 & 0,7 \\
\hline A3 & 90,2 & 80,5 & $-10,8$ & 0,1 & 90,2 & 89,5 & $-0,8$ & 1,9 & 90,2 & 85,7 & $-5,0$ & 2,3 & 90,2 & 88,3 & $-2,1$ & 0,2 & 90,2 & 84,4 & $-6,4$ & 0,3 \\
\hline A4 & 45,9 & 36,5 & $-20,5$ & 10,6 & 45,9 & 43,1 & $-6,1$ & 4,9 & 45,9 & 40,8 & $-11,1$ & 5,0 & 45,9 & 39,3 & $-14,4$ & 6,1 & 45,9 & 43,2 & $-5,9$ & 2,3 \\
\hline N1 & 64,6 & 64,3 & $-0,5$ & 2,2 & 64,6 & 64,6 & 0,0 & 1,3 & 64,6 & 56,2 & $-13,0$ & 0,5 & 64,6 & 60,3 & $-6,7$ & 0,3 & 64,6 & 56,3 & $-12,8$ & 0,4 \\
\hline N2 & 81,4 & 74,2 & $-8,8$ & 31,5 & 81,4 & 73,1 & $-10,2$ & 30,5 & 81,4 & 63,4 & $-22,1$ & 32,2 & 81,4 & 75,0 & $-7,9$ & 30,7 & 81,4 & 79,9 & $-1,8$ & 30,3 \\
\hline
\end{tabular}




\section{CONCLUSÕES}

O presente trabalho buscou determinar e comparar as propriedades petrográficas e tecnológicas de seis rochas aglomeradas e naturais, visando correlacionar tais parâmetros e compreender o desempenho desses materiais quando aplicados em obras civis.

Por extensão, os resultados deste estudo servem como ferramenta orientativa para auxiliar arquitetos e demais especificadores no conhecimento e seleção da rocha mais adequada em função do ambiente de aplicação.

De forma geral foram encontradas boas correlações entre os aspectos petrográficos e o comportamento físico-mecânico e químico dos materiais estudados, sendo que grande parte das correlações se mostraram diretas e evidentes. Confirma-se assim a importância da análise petrográfica na estimativa preliminar e orientativa para o conhecimento das propriedades tecnológicas das rochas, sejam elas aglomeradas ou naturais.

Os resultados tecnológicos permitem considerar que todos os materiais são adequados para utilização como ornamento ou revestimento em edificações. Os quartzitos em específico satisfazem com ampla margem a todos os critérios de especificação contidos na norma C616 (ASTM, 2015). Adiante são feitas algumas sugestões de aplicação para os materiais estudados observando as características de cada um, e levando-se em conta apenas os ensaios realizados.

É pertinente salientar que, ao contrário do que se propaga no meio comercial e nos catálogos fornecidos pelos fabricantes, os materiais artificiais não apresentam porosidade e absorção d'água nulas.

Comparando-se a superfície sinterizada A3 ao quartzito N2, por exemplo, os valores encontrados para a rocha natural são bastante inferiores. Assim, os materiais artificiais estão sujeitos à alteração e surgimento de patologias como as rochas naturais.

Tanto o quartzito N1 quanto N2 apresentaram excelentes propriedades físico-mecânicas, as quais atenderam aos valores de especificação da C616. Com sua elevada resistência mecânica e baixos índices de absorção d'água podem ser utilizados como material estrutural, em revestimentos verticais e horizontais de interiores, bancadas e tampos de mesa em geral.

A especificação para revestimentos exteriores carece de ensaios não realizados neste trabalho, como resistência à abrasão (pisos) e exposição à atmosferas agressivas (fachadas).

Sugere-se que a aplicação em pias ou lavabos de banheiros seja feita com cautela, mediante a aplicação prévia de impermebializantes, visto que esses ambientes estão sujeitos à produtos de limpeza e agentes manchantes que causam alteração cromática aos dois materiais, principalmente ao tipo N1. As superfícies de quartzo A1 e A2 apresentaram as resistências mecânicas mais elevadas dentre os materiais estudados e também os menores índices de porosidade e absorção d'água.

Essas características aliadas à excelente resistência química e ao manchamento permitem aplicações em revestimentos horizontais e verticais de ambientes internos, pias e bancadas de cozinhas, além de superfícies de ambientes que requerem maior rigor sanitário, como restaurantes e hospitais.

O tipo A4, devido à coloração escura, apresentou alteração cromática nos testes de resistência química e de manchamento, restringindo sua exposição aos ambientes com uso constante de sabões e outros produtos à base de amônio e hidróxido de sódio.

Por sua vez, a superfície sinterizada A3 possui boas propriedades físico-mecânicas que a tornam adequada para aplicações em painéis, bancadas e revestimentos horizontais internos. Dado a sua baixa densidade relativa $\left(2.343 \mathrm{~kg} / \mathrm{m}^{3}\right)$, seu emprego não sobrecarrega o peso global da edificação, tornando-o adequado para aplicação em pisos elevados.

Os resultados dos ensaios de resistência química e ao manchamento mostraram que este material é sensível à produtos de limpeza e também a itens alimentícios, tais como café e suco de uva, de forma que sua aplicação em pias de cozinha e banheiros requer manutenção mais cuidadosa e orientada.

\section{AGRADECIMENTOS}

Ao corpo técnico do Centro de Tecnologia Mineral - CETEM/NRES e do Instituto Federal do Espírito Santo - IFES/Campus Cachoeiro de Itapemirim pelo apoio na realização dos ensaios de caracterização tecnológica. 


\section{REFERÊNCIAS}

AMERICAN SOCIETY FOR TESTING AND MATERIALS ASTM. C616. Standard Specification for Quartz-based Dimension Stone. p. 2, 2015.

ASSOCIAÇÃO BRASILEIRA DE NORMAS TÉCNICAS ABNT. Análise petrográfica. NBR 15845, anexo A: Rio de Janeiro, p. 3-5, 2010.

ASSOCIACIÓN ESPAÑOLA DE NORMALIZACIÓN Y CERTIFICACIÓN - AENOR. UNE - EN 14617: Piedra Aglomerada - Métodos de Ensayo. Parte 1. Determinación de la densidade aparente y la absorción de agua, 2013.

ASSOCIACIÓN ESPAÑOLA DE NORMALIZACIÓN Y CERTIFICACIÓN - AENOR. UNE - EN 14617: Piedra Aglomerada - Métodos de Ensayo. Parte 2. Determinación de la resistencia a flexión, 2008.

ASSOCIACIÓN ESPAÑOLA DE NORMALIZACIÓN Y CERTIFICACIÓN - AENOR..UNE - EN 14617: Agglomerated Stone - Test Methods. Part 10: Determination of Chemical Resistance. Part 10. 2012a.

ASSOCIACIÓN ESPAÑOLA DE NORMALIZACIÓN Y CERTIFICACIÓN - AENOR. UNE - EN 14617: Agglomerated Stone - Test methods. Part 10: Determination of the Resistance to Stains. Annex A. 2012b.

ASSOCIACIÓN ESPAÑOLA DE NORMALIZACIÓN Y CERTIFICACIÓN - AENOR. UNE - EN 14618. Piedra aglomerada. Terminología y classificación, 2011.

BOLONINI, T.M \& GODOY, A. M. Caracterização tecnológica dos quartzo sienitos com hiperstênio butterfly beige e butterfly green. Geociências, v. 36, n. 3, p. 463 - 479, 2017.

CHIODI FILHO, C. Balanço das Exportações e Importações de Brasileiras de Rochas Ornamentais. Informe 01/2019. ABIROCHAS, 2019. Disp. em: $<$ https://www.abirochas.com.br/wp-

content/uploads/2018/06/Informes/Informe_01_2019_Balanco 2018.pdf >. Acessado em: 17 fev. 2020.

CIELAB - Commission International de l'Eclaraige. Recommendations on Uniform Color Spaces, Color Difference Equations, Psychometric Color Terms. Supplement 2 to CIE publication 15. Colorimetry Bureau Central de la CIE: Paris; 1976.

COSENTINO. Dekton Ficha Datos Seguridad. 2018. Disp. em: $<$ https://pro.cosentino.com/s/technicaldocumentation?language $=$ es\& $>$. Acessado em: $14 \mathrm{fev} .2020$.

DEUTSCHES INSTITUT FÜR NORMUNG - DIN. DIN EN ISO/CIE 11664-4. Colorimetry - Part 4: CIE 1976 L*a*b* colour space, 2019.

FENER, M. \& INCE, I. Influence of orthoclase phenocrysts on point load strength of granitic rocks. Engineering Geology, v. 141-142, p. 24-32, 2012.

FRASCÁ, M.H.B.O; RODRIGUES, E.P.; PALDÊS, R.J.A. Orientações para especificação de rochas ornamentais. Coleção Documentos Técnicos, Projeto Academia das Rochas, Série Arquitetura, Documento 11. Brasília: ABIROCHAS, 2019. 52 p. Disp. em: <http://cms.academiadarocha.com.br/wpcontent/uploads/2019/08/5d653d4c09bd0.pdf >. Acesso em: 19 fev 2020.
LEE, M-Y; KO, C-H; CHANG, F-C; LO, S-L; LIN, J-D; SHAN, $\mathrm{M}-\mathrm{Y}$; LEE, J-C. Artificial stone slab production using waste glass, stone fragments and vacuum vibratory compaction. Cement \& Concrete Composites, v. 30, p.583-587, 2008.

MINOLTA. Precise Color Communication: Color Control from Perception to Instrumentation. Japan: Minolta Co. Ltd., p. 59, 2007.

ONDRÁŠIK, M. \& KOPECKY, M. Rock pore structure as main reason of rock deterioration. Studia Geotechnica et Mechanica. v. 36, p. 79-88, 2014.

PAZETO, A.A. \& ARTUR, A C. Correlação entre comportamento tecnológico e propriedades petrográficas das rochas ornamentais silicáticas Branco Galaxy, Ocre Itabira e Diamante Negro. Geociências, v. 34, n. 4, p. 828-847, 2015.

SAMPAIO, A.R. Programa Levantamentos Geológicos Básicos do Brasil - PLGB. Jacobina - Folha SC.24-Y-C, Estado da Bahia. Escala 1:250.000. Organizado por A.R. Sampaio, R.A. Santos, A.J.D. Rocha, J.T. Guimarães -Brasília: CPRM/DIEDIG/DEPAT, 2001.

SANTOS, R.F. A Formação Salinas da Faixa Araçuaí, Minas Gerais: Acervo Estrutural e Significado Tectônico. 2007. 140 p. Dissertação (Mestrado em Geologia), Escola de Minas, Ouro Preto, 2007.

SIMÃO, J.A.RS. Rochas Ígneas como Pedra Ornamental Causas, Condicionantes e Mecanismos de Alteração. Implicações Tecnológicas. 2003. 182 p. Tese (Doutorado), Faculdade de Ciências e Tecnologia, Universidade Nova de Lisboa, Caparica, 2003.

SOUSA, L.M.O. The influence of the characteristics of quartz and mineral deterioration on the strength of granitic dimensional stones. Environ Earth Sci, v. 69, n. 4, p. 13331346, 2013.

TÖRÖK, A. \& VÁSÁRHELYI, B. The influence of fabric and water content on selected rock mechanical parameters of travertine, examples from Hungary. Engineering Geology, v. 115, p. 237-245, 2010.

TUGRUL, A. The effect of weathering on pore geometry and compressive strength of selected rock types from Turkey. Engineering Geology, v. 75, p. 215-227, 2004.

YILMAZ, N.G.; GOKTAN, R.M.; KIBICI, Y. Relation between some quantitative petrographic characteristics and mechanical strength of granitic building stone. International Journal of Rock Mechanics and Mining Science, v. 38, p. 671-682, 2010.

Submetido em 4 de março de 2020 Aceito para publicação em 6 de outubro de 2020 